\title{
Iodine Valence and Local Environments in Borosilicate Waste Glasses using X-ray Absorption Spectroscopy
}

\author{
David A. McKeown*, Isabelle S. Muller, and Ian L. Pegg \\ Vitreous State Laboratory, The Catholic University of America, \\ 620 Michigan Ave, N.E., Washington, D.C. 20064
}

* corresponding author:

Phone: (202) 319-5226, FAX: (202) 319-4469; e-mail: davidm@vsl.cua.edu

\section{Abstract}

The radioisotope ${ }^{129} \mathrm{I}$, a fission product in spent nuclear fuel, has a long half-life, and can be highly mobile in the environment. Iodine K-edge X-ray absorption spectra were collected to characterize the iodine valence and coordination environment in simulated Hanford low activity waste glasses. Both iodine XANES and EXAFS data for eleven borosilicate glasses indicate iodide-like environments within the glass structure, where ${ }^{-}$ has $\mathrm{Na}$ or Li nearest-neighbors, and where the nearest-neighbor cation-type correlates to the most common network-modifying cation in the glass. This is further supported by the systematic increase of iodine incorporation with the combined $\mathrm{Na}_{2} \mathrm{O}+\mathrm{Li}_{2} \mathrm{O}$ content in the glass. EXAFS analyses determined I-Na distances near $3.04 \AA$ with coordination numbers near 4.0 and I-Li distances near $2.80 \AA$ with coordination numbers near 3.0. I-Na environments determined for the glasses are similar to the tetrahedral $\mathrm{INa}_{4}$ coordination 
found in NaI-sodalite. These weakly bound iodine-alkali configurations may be the only pathways for iodine to be retained in the glass. These environments may be precursors to NaI-sodalite crystallization in Na-rich glass. Iodine also shows distinct differences from chlorine in terms of the preferred sites in the glass structure. 


\section{Introduction}

The radioactive iodine isotope ${ }^{129} \mathrm{I}$ is formed by fission of uranium and plutonium in nuclear reactors and it is therefore present in many types of nuclear wastes. It is a $\beta$-emitter with a half-life of 15.7 million years and, since iodine forms very soluble anions such as iodide $\left(\mathrm{I}^{-}\right)$, it is highly mobile in the environment. The long half-life and high environmental mobility coupled with the biological activity of iodine, particularly in the thyroid, make ${ }^{129}$ I a significant environmental risk factor in the performance assessment of repositories for nuclear waste disposal.

At the Hanford site in Washington State, about 56 million gallons of high-level nuclear waste generated from production of weapons materials is in storage in 177 underground tanks. The Hanford Tank Waste Treatment and Immobilization Plant (WTP) that is under construction is designed to separate the waste into low-activity waste (LAW) and high-level waste (HLW) fractions that will be stabilized in separate LAW and HLW borosilicate glasses by vitrification. Since ${ }^{129} \mathrm{I}$ is also a constituent of concern in the Hanford waste [1], understanding its fate in the vitrification processes and mode of incorporation into the glass waste forms is of importance. Iodine is quite volatile under the high temperature $\left(\sim 1150^{\circ} \mathrm{C}\right)$ glass melting conditions and a significant fraction will be partitioned to the off-gas from the WTP glass melters and subsequently captured in the offgas treatment systems. The WTP is designed to recycle liquid effluents from off-gas treatment back to the melter feed in order to increase the incorporation of volatile species such as ${ }^{129} \mathrm{I}$ into the glass product. In view of the very low concentrations of ${ }^{129} \mathrm{I}$ expected in the glass products (of the order of $1 \mathrm{ppm}$ in the LAW glass, for example), which is far below its typical solubility [2], volatility, rather than solubility, is the primary factor 
limiting its incorporation into glass. In the present work, a series of iodine-containing simulated LAW glasses were investigated using X-ray absorption spectroscopy (XAS) in order to characterize iodine valence and bonding environments. The samples studied included glasses that were prepared in small-scale continuous joule-heated ceramic melting systems that included off-gas treatment systems and effluent recycle prototypical of the plan for the WTP [3].

An X-ray absorption spectrum can be divided into two regions: the X-ray absorption near edge structure (XANES) that includes an absorption edge of the element of interest (in this case, iodine) and the extended X-ray absorption fine structure (EXAFS). Typically, the edge energy is sensitive to the valence of the absorbing element, which increases with the higher valence of the absorber. Features at the absorption edge are also sensitive to the local atomic environment surrounding the absorbing element. The EXAFS data, by convention, are extracted from a spectrum at approximately $20 \mathrm{eV}$ beyond the absorption edge to higher energies. In many cases, EXAFS oscillations are due primarily to single scattering of the spherical electron wave emitted by the absorbing atom from the arrangement of surrounding atoms. Through fitting procedures, EXAFS data for this study are analyzed to quantitatively determine average bond distance $(r(\AA))$, coordination number ( $n$ (atoms)), and disorder (Debye-Waller factor or $\left.\sigma^{2}\left(\AA^{2}\right)\right)$ of shells of nearestneighbor atoms around iodine.

A number of earlier studies used XAS to characterize iodine in a wide variety of samples [4-13], including iodine sorption in cement materials [4], iodine in LAW borosilicate glass [5], as well as iodine in spent solvent from nuclear fuel reprocessing [10]. The XAS studies of iodide $\left(\mathrm{I}^{-}\right)$and iodate $\left(\mathrm{IO}_{3}{ }^{-}\right)$sorption in hardened cement paste (HCP) and calcium silicate hydrate ( $\mathrm{CSH})$ materials [4] as well as iodine in borosilicate glass [5] 
are of particular interest because of the general chemical similarity of those materials to the glasses investigated here.

The motivation behind the iodine K-edge XAS study of CSH and HCP, was that cement materials can act "as a chemical barrier to radionuclides, retarding migration of toxic and radioactive ions into the far-field" [4]. The up-take of iodine species in solution under highly alkaline conditions by $\mathrm{CSH}$ and $\mathrm{HCP}$ was measured, where $\mathrm{I}^{-}$was anticipated, while under more oxidizing conditions, $\mathrm{I}^{5+}$ in $\mathrm{IO}_{3}{ }^{-}$was anticipated. The study [4] showed that iodine K-edge XANES can distinguish iodide (nearly featureless edges) from iodate (edge peak and interference oscillations). EXAFS data and analyses results were presented only for samples containing iodate, where I-O distances determined were near $1.79 \AA$ with $n \sim 3$. For iodide-containing samples, only a narrow EXAFS k-range could be analyzed due to the weak signal, which limited the authors to conclude that iodine nearest-neighbor distances are long (> $3 \AA$ ) in the cement samples. Overall, XAS showed that there was no iodine valence change during the sorption of $\mathrm{I}^{-}$or $\mathrm{IO}_{3}{ }^{-}$from solution into $\mathrm{CSH}$ or $\mathrm{HCP}$. However, $\mathrm{IO}_{3}{ }^{-}$appeared to be bonded directly to $\mathrm{CSH}$, while behaving in the HCP samples more as a freely solvated ion in solution; both iodate environments in these materials are similar to those in the crystalline iodate standards measured.

The iodine K-edge XANES study of LAW borosilicate glasses [5] characterized iodine environments in crystal-free glasses and samples with crystals on a surface layer as well as suspended in the glass. Even though iodine was introduced as KI in these samples, XANES fitting routines indicate that crystalline NaI was the closest match to the crystalfree glasses, indicating I-Na environments the glass structure. Inclusions within some of the 
samples were crystalline NaI-sodalite $\left(\mathrm{Na}_{8}\left(\mathrm{Si}_{6} \mathrm{Al}_{6} \mathrm{O}_{24}\right) \mathrm{I}_{2}\right)$, where $\mathrm{I}$ is tetrahedrally coordinated by four $\mathrm{Na}^{+}$within an aluminosilicate cage structure [14].

Considering the chemistry of the glasses investigated, results from earlier studies, and the variety of possible valences and bond environments in nature, iodine in glass can be bonded to itself, to oxygen bound or unbound to the borosilicate network, or to network modifying cations: $\mathrm{Li}, \mathrm{Na}, \mathrm{K}$, and $\mathrm{Ca}$. To the best of our knowledge, there is no evidence in the literature for elemental $\mathrm{I}_{2}$ or iodate in borosilicate waste glass structure. In the present work, seven crystalline standards were measured to model these possible I valences and environments in the borosilicate glasses investigated, that include $\mathrm{I}_{2}$; the iodides: NaI, KI, and $\mathrm{CaI}_{2}$; and the iodates: $\mathrm{KIO}_{3}, \mathrm{NaIO}_{3}, \mathrm{Ca}\left(\mathrm{IO}_{3}\right)_{2}$. It was determined that the original $\mathrm{NaI}$ and $\mathrm{CaI}_{2}$ reagents were altered to $\mathrm{NaI} \cdot 2\left(\mathrm{H}_{2} \mathrm{O}\right)$ and $\mathrm{CaI}_{2} \cdot 4\left(\mathrm{H}_{2} \mathrm{O}\right)$, respectively. Even though these iodide phases have altered structures compared with their original counterparts, they can be used as standards, since Na-I and Ca-I bonds are present that can model the possible equivalent environments in the glasses.

The structures of the standards used for this study have iodine in a variety of environments. Elemental iodine contains $\mathrm{I}_{2}$ molecules, where I-I distances are $2.68 \AA$ with a separation of $3.50 \AA$ between neighboring $\mathrm{I}_{2}$ molecules in the crystal structure [15]. The iodates $\mathrm{NaIO}_{3}, \mathrm{KIO}_{3}, \mathrm{Ca}\left(\mathrm{IO}_{3}\right)_{2}$, all have $\mathrm{IO}_{3}{ }^{-}$trigonal pyramids, where three oxygens are bonded to an apical I with I-O distances near $1.81 \AA$ [16-19], so that the iodate groups are surrounded by alkali and alkaline earth cations that are major elemental components in the glasses studied. The NaI and KI rock-salt structures have I surrounded by six $\mathrm{Na}^{+}$and six $\mathrm{K}^{+}$, respectively, where I-Na is $3.24 \AA$ and I-K is $3.53 \AA$ in these octahedral environments 
$[20,21]$. In contrast with $\mathrm{NaI}$, the $\mathrm{NaI} \cdot 2\left(\mathrm{H}_{2} \mathrm{O}\right)$ structure [22] has six-coordinated $\mathrm{Na}$ with four water molecules (Na-O distances ranging from 2.37 to $2.54 \AA$ ) and two I atoms (with Na-I $=3.21$ and $3.26 \AA)$. The $\mathrm{CaI}_{2} \cdot 4\left(\mathrm{H}_{2} \mathrm{O}\right)$ structure [23] is comprised of elongated Ca octahedra that include two I atoms at the apices of the octahedron, where I-Ca is $3.13 \AA$, and four shorter equatorial water molecules at $2.30 \AA$ from the $\mathrm{Ca}$; therefore, iodine in this structure has $n=1$, or one Ca atom.

\section{Experimental}

The crystalline standards, $\mathrm{I}_{2}$ (Sigma-Aldrich), KI (Alfa-Aesar), $\mathrm{NaIO}_{3}$ (SigmaAldrich), $\mathrm{Ca}\left(\mathrm{IO}_{3}\right)_{2}$ (Strem Chemical Co.), and $\mathrm{KIO}_{3}$ (Alfa-Aesar) were verified using Xray diffraction (XRD). The $\mathrm{NaI}$ (Fisher Scientific) and $\mathrm{CaI}_{2}$ (Sigma-Aldrich) crystalline reagents were found by XRD to be $\mathrm{NaI} \cdot 2\left(\mathrm{H}_{2} \mathrm{O}\right)$ and $\mathrm{CaI}_{2} \cdot 4\left(\mathrm{H}_{2} \mathrm{O}\right)$, respectively, with little, if any, evidence of the original reagent.

The compositions of the eleven glasses investigated, shown in Table 1, were based on those developed and tested previously for treatment of Hanford WTP LAW streams $[24,25]$. The glasses were determined to be amorphous by XRD, except for NaI2 and NaI-6, which appear to have trace amounts $(<0.1$ wt.\%) of spinel crystals. Two glasses, 10S-G-86F and 10T-G-106C, were synthesized in a continuously-fed ceramic refractory-lined joule-heated DM10 melter that produced glass at a rate of about $50 \mathrm{~kg}$ per day [3]. The tests employed simulated LAW streams representing pretreated 
supernate from Hanford tank AZ-102 (glass 10S-G-86F) and tank AP-101 (glass 10S-G106C) [3]. These streams are essentially high-sodium salt solutions containing many components but predominantly nitrate, nitrite, hydroxide, aluminum, and phosphorus; AZ-102 is higher in sulfate while AP-101 is higher in potassium. The melter feed material was an aqueous slurry of the simulated waste mixed with glass forming chemicals, which is pumped continuously onto the surface of the molten borosilicate pool in the melter. The energy required to melt the feed is dissipated by resistance heating by passing an electric current between Inconel 690 plate electrodes that are submerged in the molten glass pool. An air-bubbler was used to stir the melt and increase the glass production rate. The melter was fitted with an off-gas treatment system that included a submerged bed scrubber (SBS), wet electrostatic precipitator (WESP), and HEPA filtration. The liquid effluents from the SBS and WESP were concentrated in a vacuum evaporator in real time and the concentrate was recycled back to the melter feed. The iodine content in the melter feed was equivalent to $0.1 \mathrm{wt} \%$ in the glass if all of it were retained; the analyzed iodine contents in the two selected glasses were $84 \%$ and $49 \%$ of that value for $10 \mathrm{~S}-\mathrm{G}-86 \mathrm{~F}$ and $10 \mathrm{~T}-\mathrm{G}-106 \mathrm{C}$, respectively. Given the high volatility of iodine, these high retentions under realistic processing conditions are noteworthy and particularly so in view of the fact that the melt pool was stirred with an air bubbler. Iodine retention in glass increased significantly with run time, as steady-state conditions were approached, and was significantly higher with recycling than without [3], as would be expected.

The nine other glasses were synthesized by melting the appropriate reagent grade chemicals in Pt-Au crucibles. To improve signal-to-noise ratios in the XAS data by increasing the amount of iodine retained in the glass, the crucible glasses were batched with excess iodine in order to compensate for the substantial losses by evaporation during melting. The crucible melts were prepared using mixtures of $\mathrm{Al}_{2} \mathrm{O}_{3}, \mathrm{H}_{3} \mathrm{BO}_{3}, \mathrm{CaCO}_{3}$, 
$\mathrm{KOH}, \mathrm{LiCO}_{3}, \mathrm{SiO}_{2}, \mathrm{ZnO}$, with either $\mathrm{Zr}(\mathrm{OH})_{4}$ or $\mathrm{SnO}_{2}$. Sodium was added as $\mathrm{NaOH}$ (50\% solution) for NaI-1, NaI-2, NaI-3, NaI-6, KI-2 and KI-3 glasses, or as $\mathrm{NaNO}_{3}$ for all other glasses. The different reagents were used to introduce iodine into the various crucible glass recipes and to investigate possible effects on the iodine environments in the resulting glasses: KI was used for KI-2, KI-3, and KI-4; NaI was used for NaI-1, NaI-2, NaI-3, and NaI-6; and $\mathrm{NH}_{4} \mathrm{IO}_{3}$ was used for NaI-5 and KI-5. In NaI-6 glass, $\mathrm{SnO}_{2}$ was used in place of $\mathrm{ZrO}_{2}$ to investigate the possibility of forming $\mathrm{SnI}_{4}$ tetrahedra [26].

The glass compositions reported (Table 1) were determined by X-ray fluorescence (XRF) except for $\mathrm{B}_{2} \mathrm{O}_{3}$ and $\mathrm{LiO}_{2}$, which are the target values adjusted by normalization to the measured iodine content. The resulting iodine content measured in the glasses $(0.03$ to $0.66 \mathrm{~mol} \%$ ) did not appear to be sensitive to changes in batching chemistry, except for $\mathrm{Na}_{2} \mathrm{O}$ and $\mathrm{Li}_{2} \mathrm{O}$ content, as discussed in Section 4.2.2. Due to the relatively low iodine concentrations in the glasses, no self-absorption effects are expected in the X-ray absorption spectra collected in fluorescence mode. As a result, glass fragments were used for the XAS measurements to obtain the best signal-to-noise spectra and were taken from clear, homogeneous portions of each sample.

Iodine K-edge fluorescence XAS data were collected on beam line X18-B at the National Synchrotron Light Source (NSLS), Brookhaven National Laboratory. Since the glasses contain $\mathrm{Ca}$, iodine $\mathrm{K}$-edge spectra were measured to avoid $\mathrm{Ca} \mathrm{K}$-edge interference with iodine L-edge features. During data collection, synchrotron conditions were at $2.80 \mathrm{GeV}$ with ring currents ranging from 305 to $200 \mathrm{~mA}$. Monochromator scan ranges were different depending on the iodine content of the samples measured. Data were initially collected on the standards to include the iodine K-edge $(33,169 \mathrm{eV})$ at a relatively 
wide energy range, where the double crystal Si (111) monochromator was scanned from $150 \mathrm{eV}$ below the edge to $700 \mathrm{eV}$ above the edge. The scans used a $2 \mathrm{eV}$ point spacing at 2 second collection time per data point from $15 \mathrm{eV}$ below to $150 \mathrm{eV}$ above the K-edge, and $3 \mathrm{eV}$ point spacing at 3 second collection time per point at energies greater than 150 $\mathrm{eV}$ above the edge. A minimum of three XAS spectra were collected for each crystalline standard. As the glasses were measured, it became clear that the EXAFS features did not extend as far as those for the iodate standards, so the scans were shortened to an energy maximum of $440 \mathrm{eV}$ above the K-edge. To maximize signal-to-noise ratios in the XANES (Figs. 1-3) and EXAFS data (Figs. 4-6) for the glasses, the number of scans for each glass was increased from four to 40 as iodine concentrations decreased.

Incident and transmitted X-ray intensities $\left(\mathrm{I}_{0}\right.$ and $\mathrm{I}_{\mathrm{t}}$, respectively) were measured using ion chambers, which were placed in the photon beam up-stream and down-stream of the sample, respectively. The fluorescence X-ray intensity $\left(\mathrm{I}_{\mathrm{f}}\right)$ from each sample was measured using a passivated implanted planar silicon (PIPS) detector, where the normal to the flat surface of the detector was positioned $90^{\circ}$ from the incident X-ray beam, while the flat sample tape or glass surface was placed at a $45^{\circ}$ angle with respect to the incident beam, and between the $I_{0}$ and $I_{t}$ ion chambers. For energy calibration purposes, a third "reference" ion chamber $\left(I_{R}\right)$ was downstream of the $I_{t}$ chamber, where the crystalline $I_{2}$ standard was placed between the $I_{t}$ and $I_{R}$ detectors so that transmission data of this standard were collected in parallel with the fluorescence and transmission data for each sample. The absorption coefficient ( ) of the sample at a particular energy is proportional to $\mathrm{I}_{\mathrm{f}} / \mathrm{I}_{0}$; and the corresponding of the iodine standard at each energy is $-\ln \left(\mathrm{I}_{\mathrm{R}} / \mathrm{I}_{\mathrm{t}}\right)$. The $\mathrm{X}$ ray absorption spectrum is a plot of versus energy in eV. For every sample, each 
spectrum was energy-calibrated to the first derivative maximum of the $\mathrm{I}_{2} \mathrm{~K}$-edge [27]. The energy uncertainty for the data presented here is within $\pm 2 \mathrm{eV}$; and the spectral resolution at the iodine K-edge is approximately $6.6 \mathrm{eV}$.

\subsection{Sample Alteration Issues}

Iodides can absorb water when exposed to air, which was the case for the $\mathrm{NaI}$ and $\mathrm{CaI}_{2}$ reagents used. Since most glasses synthesized for this study have $\mathrm{Na}$ as the dominant network modifying cation, it was desirable to collect XAS data on NaI. Consequently, an attempt was made to restore the $\mathrm{NaI} \cdot 2\left(\mathrm{H}_{2} \mathrm{O}\right)$ powder to the original $\mathrm{NaI}$, before the XAS measurements. The NaI $\cdot 2\left(\mathrm{H}_{2} \mathrm{O}\right)$ powder was placed in a $105{ }^{\circ} \mathrm{C}$ oven for over 3 days to drive off water and restore the $\mathrm{NaI}$ (verified by XRD). The powder was then mounted and sealed in tape as well as in small plastic bags. XAS data were collected on the restored $\mathrm{NaI}$ sample three days after the heat treatment. Unfortunately, the EXAFS data for the heated NaI sample (Figs. 4a and 5a) has features consistent with the $\mathrm{NaI} \cdot 2\left(\mathrm{H}_{2} \mathrm{O}\right)$ structure, and not with $\mathrm{NaI}$. Therefore, re-hydration of the heated $\mathrm{NaI}$ powder took place quickly enough that the sample became dominated by $\mathrm{NaI} \cdot 2\left(\mathrm{H}_{2} \mathrm{O}\right)$ at the time of the XAS data collection; this re-hydration process was verified by XRD.

Photo-redox reactions of some iodides exposed to X-rays have also been reported [7]. This process occurs for $\mathrm{KI}$, which partially oxidizes to a mixture of $\mathrm{KI}$ and $\mathrm{I}_{2}$ in minutes when exposed to X-rays at energies near the iodine L-edge; physical changes to the sample and changes in the XAS data features were seen over time. These reactions did not occur, however, for KI exposed to X-rays at energies near the iodine K-edge. 
In response to these potential problems, the samples measured for this study were closely monitored for any alteration effects in the incident X-ray beam. Other than $\mathrm{CaI}_{2} \cdot 4\left(\mathrm{H}_{2} \mathrm{O}\right)$, there was no physical sign of the standards altering in the incident beam as well as no sign of changes to the XAS data as multiple scans were collected for each sample. The $\mathrm{CaI}_{2} \cdot 4\left(\mathrm{H}_{2} \mathrm{O}\right)$ sample changed texture and color in the incident beam after 20 to 30 minutes; therefore, a fresh portion of this sample was moved into the beam for the next scan. For most glasses, the portion of each fragment exposed to the X-ray beam turned dark (probably due to color centers) after several XAS scans; however, no changes in the data were observed from the first to last scan for each glass.

\section{Data Analysis}

The XANES spectra presented are averages of the data sets collected from each sample. Each XAS spectrum was processed using standard pre-edge background subtraction and edge-step normalization procedures [28]. The K-absorption edge first derivative inflection point in each $\mathrm{I}_{2}$ calibration spectrum, was set to $33,169 \mathrm{eV}$ and defined as $\mathrm{E}_{0}$, to energy-calibrate each XANES spectrum for the sample. After normalization and calibration, direct comparisons can be made with XANES data for all samples measured to an energy accuracy of $\pm 2 \mathrm{eV}$, or the energy difference between two adjacent data points at the K-edge (Figs. 1-3).

A cubic spline function was fit to and then subtracted from all edge-step normalized data at approximately 25 to $440 \mathrm{eV}$ above $\mathrm{E}_{0}$. Energy values in $\mathrm{eV}$ were then converted to

$\mathrm{k}\left(\AA^{-1}\right)[28]$, where the resulting $\chi(\mathrm{k})$ data was $\mathrm{k}^{2}$-weighted (Figs. 4a to d). $\mathrm{k}^{2} \chi(\mathrm{k})$ data 
ranges used for the EXAFS analysis fitting varied depending on the extent of the EXAFS oscillations in the data as well as how well the theory modeled the data. For the iodate standards, where the EXAFS oscillations were the largest, the widest k-range in this study was used: $1.5 \leq \mathrm{k} \leq 13.0 \AA^{-1}$ (Figs. $4 \mathrm{~b}$ and $5 \mathrm{~b}$ bottom)). For the $\mathrm{I}_{2}$ and iodide standards, with considerably smaller EXAFS amplitudes, narrower k-ranges were used: $2.5 \leq \mathrm{k} \leq 9.0$ $\AA^{-1}$ for $\mathrm{NaI} \cdot 2\left(\mathrm{H}_{2} \mathrm{O}\right), 2.7 \leq \mathrm{k} \leq 10.5 \AA^{-1}$ for $\mathrm{KI}, 1.5 \leq \mathrm{k} \leq 7.5 \AA^{-1}$ for $\mathrm{CaI}_{2} \cdot 4\left(\mathrm{H}_{2} \mathrm{O}\right)$, and $1.5 \leq$ $\mathrm{k} \leq 8.5 \AA^{-1}$ for $\mathrm{I}_{2}$ (Figs. $4 \mathrm{a}$ and b). Due to structural disorder in the glasses that have Na as the most common network modifying cation, EXAFS k-ranges were also narrow: from 1.5 $\leq \mathrm{k} \leq 9.0 \AA^{-1}$ for the most I-rich glass, NaI-3 (Fig. 6a bottom), to $1.5 \leq \mathrm{k} \leq 6.0 \AA^{-1}$ for the most I-poor glasses (for example: KI-5 glass). For the two glasses that have Li as the most common network modifying cation, KI-2 and 10S-G-86F, oscillations did not extend much beyond $5.0 \AA^{-1}$; as a result, the k-range used for the EXAFS analyses of these glasses was: $1.5 \leq \mathrm{k} \leq 5.5 \AA^{-1}$ (Fig. 6b). A Hanning window of $1.0 \AA^{-1}$ was used on the upper and lower limits of all $\mathrm{k}^{2} \chi(\mathrm{k})$ data to minimize Fourier-transform termination artifacts in the resulting partial radial distribution function (RDF) (Figs. 5a, 5b top, 6a top, and 6b top).

IFEFFIT $[29,30]$ was used to fit the $\mathrm{k}^{2} \chi(\mathrm{k})$ and partial RDF data for the standards and glasses, to obtain EXAFS parameters $\mathrm{s}_{0}{ }^{2}$ and $\mathrm{E}_{0}$, as well as the structural parameters $r$, $n$, and $\sigma^{2}$ for each important pair correlation. Initially, fitting the standards data started by constraining $r$ and $n$ to the values from the crystal structure, while $\mathrm{s}_{0}{ }^{2}$ and $\mathrm{E}_{0}$ were varied. To obtain reasonable coordination numbers, $\mathrm{s}_{0}{ }^{2}$ was found to be 1.0 and then constrained to that value for all EXAFS fits (Tables 2-4), where $r, n$, and $\sigma^{2}$ were varied. To obtain reasonable $r$ values and good fits of the calculated EXAFS to the experimental data for the 
standards, $\mathrm{E}_{0}$ values were found to vary with respect to the iodine valence: from 3.5 to -6.0 $\mathrm{eV}$ for the more reduced $\mathrm{I}_{2}$ and iodide standards, and $14.0 \mathrm{eV}$ for the oxidized iodates (Tables 2-3). For the Na-dominated and Li-dominated network modifier cation glasses, $\mathrm{E}_{0}$ values at 1.0 and $5.6 \mathrm{eV}$, respectively, were found to best fit the data and are near the range

determined for the more reduced $\mathrm{I}_{2}$ and iodide standards. $r, n$, and $\sigma^{2}$, as well as $\mathrm{E}_{0}$ in some instances, were varied to best fit the nearest-neighbor peaks in the partial RDFs for the glasses (Table 4, Figs. 6a and b).

Many iodine correlation models were tried during the EXAFS fitting of the data for the glasses due to the different atomic species that could bond to iodine. In all cases, I-Na and I-Li correlation models provided the best fits to the glass EXAFS data, resulting in physically reasonable structural parameters. On the other hand, I-I, I-K, and I-Ca models frequently resulted in poor fits as well as structural parameters that were unphysical (for example, $n<0)$.

\section{Discussion}

\subsection{XANES}

The iodine K-edge XANES spectra collected for the crystalline standards (Fig. 1) are similar to those reported previously [4, 5, 7-12]. Due to shorter core-hole lifetimes during X-ray absorption processes for higher atomic number elements, such as iodine, XANES features are broadened [31]. As a result, it is difficult to observe clear iodine K-edge energy shifts among the samples measured. However, XANES for the standards can be divided into two groups according to distinctive features at or near the edge. The 
iodate $\left(\mathrm{IO}_{3}\right)$ phases have an edge peak near $33,176 \mathrm{eV}$, as well as relatively large interference oscillations that extend well beyond the XANES energy range (Fig. 1). Conversely, the more reduced standards, $\mathrm{I}_{2}, \mathrm{NaI}_{2} \cdot 2 \mathrm{H}_{2} \mathrm{O}, \mathrm{KI}$, and $\mathrm{CaI}_{2} \cdot 4 \mathrm{H}_{2} \mathrm{O}$, have nearly featureless edges with weak oscillation amplitudes at energies higher than the edge-step.

XANES features for the glasses (Figs. 2 and 3) are most similar to those for the iodides, especially $\mathrm{KI}$ and $\mathrm{NaI} \cdot 2\left(\mathrm{H}_{2} \mathrm{O}\right)$, indicating no evidence of iodate in the glasses measured. This finding is consistent with Raman spectra gathered on these glasses (unpublished data, not shown), where no differences were observed between iodinecontaining and iodine-free glass pairs. Due to iodate group symmetry, we would anticipate high Raman sensitivity to any $\mathrm{IO}_{3}{ }^{-}$present in the glass structure. These findings are also consistent with earlier iodine XANES comparisons for borosilicate glasses [5], where the NaI XANES best matched the spectra for LAW glasses. Subtle, but consistent, differences of XANES features observed in the glass spectra can be used to divide the glasses into two groups that correlate to the majority network-modifying cation species. XANES for the nine Na network-modifier dominated (or Na-dominated) glasses (Fig. 3, black spectra) are nearly identical with respect to each other and have slightly different oscillation features at energies just above the edge near $33,184 \mathrm{eV}$, than the XANES for the two Li networkmodifier dominated (or Li-dominated) glasses (Fig. 3, red spectra).

\subsection{EXAFS}

\subsubsection{Standards}


The $\mathrm{k}^{2} \chi(\mathrm{k})$ standards data (Figs. $4 \mathrm{a}$ and b) vary considerably with respect to each other, reflecting the different atomic arrangements surrounding iodine in these phases. Similar to the XANES, the data can be divided into two groups according to the EXAFS amplitudes: one, $\mathrm{I}_{2}$ and the iodides, and two, the iodates. The iodates have EXAFS oscillations that are approximately an order of magnitude larger than the EXAFS for the other standards (Figs. 4b); this effect is caused by the $1 / \mathrm{r}^{2}$ dependence of EXAFS amplitudes [32]. $\mathrm{I}_{2}$ and the iodides have long I-I, I-Na, I-K, and I-Ca nearest-neighbor distances, from 2.68 to $3.53 \AA$, compared with the considerably shorter I-O distances near $1.80 \AA$ in the iodates. Relatively simple one frequency $\mathrm{k}^{2} \chi(\mathrm{k})$ oscillations are seen for $\mathrm{I}_{2}$, $\mathrm{KI}, \mathrm{CaI}_{2} \cdot 4\left(\mathrm{H}_{2} \mathrm{O}\right)$, and the iodates, while features for $\mathrm{NaI} \cdot 2\left(\mathrm{H}_{2} \mathrm{O}\right)$ follow a complex beat pattern indicating two similar I- Na distances.

The RDFs for the standards (Figs. 5a and b top) generally show one nearest-neighbor peak, except for NaI·2( $\left.\mathrm{H}_{2} \mathrm{O}\right)$, which has two peaks near 2.2 and $2.9 \AA$. EXAFS fitting results for the standards replicate the major features in both the partial RDFs and $\mathrm{k}^{2} \chi(\mathrm{k})$ data (Figs. 4a, 5a, and 5b). The structural parameters determined from the fitting (Tables 2 and 3) show close agreement with respect to crystal structure determinations and earlier EXAFS findings for the iodates [13,16-18], reasonably good agreement for $\mathrm{I}_{2}$ and $\mathrm{CaI}_{2} \cdot 4\left(\mathrm{H}_{2} \mathrm{O}\right)[15,23]$, and not as good agreement for the nearest-neighbor coordination number for KI [21]. The EXAFS signal from I-I second nearest-neighbors in the KI structure was strong enough to be seen near $4.8 \AA$ in the KI RDF (Fig. 5a, second plot from top) and to determine $r$ and $n$ values that are in reasonable agreement with the crystal structure [21] (Table 2). The EXAFS fitting results for $\mathrm{NaI} \cdot 2\left(\mathrm{H}_{2} \mathrm{O}\right)$ had the poorest agreement of the standards measured 
with respect to actual distances and coordination numbers for the two iodine-sites in this crystal structure [22] (Tables 2 and 3, Fig. 7). This poor agreement for $\mathrm{NaI} \cdot 2\left(\mathrm{H}_{2} \mathrm{O}\right)$ may be due to the sample being a mixture of mostly $\mathrm{NaI} \cdot 2\left(\mathrm{H}_{2} \mathrm{O}\right)$ with some residual $\mathrm{NaI}$ from the rehydration process; the exact extent of the rehydration was not known at the time of the EXAFS data collection; hence, the "?" captions added to the $\mathrm{NaI} \cdot 2\left(\mathrm{H}_{2} \mathrm{O}\right)$ results plotted in Figure 7.

Overall, the difference in agreement between EXAFS determined and actual crystal structure parameters of the iodine environments is linked to the magnitude of EXAFS amplitudes. The iodates, with large EXAFS amplitudes, have close agreement, while for the standards in which iodine is more reduced, with small EXAFS amplitudes and lower signal-tonoise levels, the agreement can be not as good (Tables 2 and 3, and Fig. 7).

\subsubsection{Glasses}

EXAFS oscillations for the Na-dominated network-modifier glasses are comparable to those for KI, and extend over a narrower k-space range compared with the standards (Fig. 4c). Similar to the XANES, the glasses can be divided into the Na- and Li-dominant network modifier groups according to the EXAFS features (Fig. 4d). The Na-dominated glasses have oscillations that extend to approximately $8 \AA^{-1}$ for the most I-rich glass, NaI-3 (Fig. 6a bottom), with narrower k-space ranges as iodine concentrations diminish (Fig. 4d top). Li dominated glasses have EXAFS extending to only $5 \AA^{-1}$, where amplitudes are damped somewhat near $3.4 \AA^{-1}$ compared with equivalent features in the Na-dominated glasses EXAFS data. Different iodine nearest-neighbor pair correlations were tried during 
the fitting routines, where I-Na worked best for the Na-dominated glasses and I-Li worked best for the Li-dominated glasses. EXAFS fitting results describe the major features in the $\mathrm{k}^{2} \chi(\mathrm{k})$ and RDF data for the glasses (Figs. 6a and b). The I-Na model for the Na-dominated glasses resulted in $r$ ranging from 3.02 to $3.08 \AA, n$ from approximately 3 to 6 , and $\sigma^{2}$ values that are mostly larger than those determined for the iodide crystalline standards (Tables 2 and 4).

Both I-Li and I-Na pair correlations provided reasonable fits and final fitting parameters for the two Li-dominated glasses, K-2 and 10S-G-86F. However, the I-Li model was a better match to the features in the $\mathrm{k}^{2} \chi(\mathrm{k})$ and RDF data for these two glasses that resulted in lower r-factor values (for example, KI-2 glass, Table 4). Overall, $r$ (near $2.80 \AA$ ) as well as $n$ (near 3 atoms) are smaller for the Li-dominated glasses than the Na-dominated glasses (Table 4 and Fig. 7). Compared with the crystalline iodides, NaI and LiI, the iodine environments in the glasses have shorter nearest-neighbor distances as well as smaller coordination numbers (Fig. 7). This finding is consistent with iodine XANES observations made between crystalline $\mathrm{NaI}$ and LAW borosilicate glasses [5]. Considering the weak EXAFS signal of samples with iodide and iodide-like environments, and the differences in the EXAFS determined I-Na and $\mathrm{I}-\mathrm{K}$ distances for $\mathrm{NaI} \cdot 2\left(\mathrm{H}_{2} \mathrm{O}\right)$ and $\mathrm{KI}$ with respect to the actual distances, uncertainties for EXAFS determined $r$-values for the glasses are likely larger than those reported by IFEFFIT (Table 4) and are estimated to be near $\pm 0.10 \AA$.

A previous LAW glass iodine XANES study [5] observed NaI-sodalite crystals suspended in some of the glasses measured, which is interesting when considering the EXAFS fitting results for the glasses investigated here (Table 4 and Fig. 7). The tetrahedral $\mathrm{INa}_{4}$ environment in NaI-sodalite has $r_{\mathrm{I}-\mathrm{Na}}=3.09 \AA$ and $n=4[14]$ that are similar to the 
EXAFS determined $r$ - and $n$-values for the iodine environments in the Na-dominated glasses investigated in this study; this is especially true for NaI-3 glass $(r=3.04 \AA$ and $n=$ 4.0) which has the highest iodine concentration and best signal-to-noise data. By considering the uncertainties of the EXAFS fitting parameters for the glasses, the $3.09 \AA$ I-Na distance in NaI-sodalite falls within the estimated $\pm 0.10 \AA$ uncertainty for the EXAFS determined I-Na distances for the Na-dominated glasses. Coordination numbers determined for the Na-dominated glasses vary from 3.2 and to 6.2, that generally have larger uncertainties at the extreme values; therefore, many of these $n$-values are statistically equivalent to 4.0. Even though there is no evidence of crystalline sodalite phases in any of the glasses measured here, the iodine EXAFS findings for the Na-dominated glasses may indicate precursors of NaI-sodalite crystallization, at least from the perspective of iodine.

Other than the $\mathrm{Na}$ and Li network modifiers in these glasses, no other correlations to iodine can be made between the XAS results and the various chemical components in the glasses measured. No discernable structural difference around iodine was found whether the glasses were prepared from iodide reagents or from ammonium iodate. Other composition differences such as significant amounts of $\mathrm{Fe}_{2} \mathrm{O}_{3}$ and $\mathrm{TiO}_{2}$ present in the two melter glasses, as well as $\mathrm{SnO}_{2}$ in NaI-6, glass, also did not yield any significant differences in the iodine sites in these glasses.

Overall, findings from iodine K-edge XANES and EXAFS indicate the important role of $\mathrm{Na}$ and $\mathrm{Li}$ in facilitating the retention of iodine in the glass structure. These observations are further supported by the roughly linear relationship between measured iodine concentrations and the $\mathrm{Na}_{2} \mathrm{O}+\mathrm{Li}_{2} \mathrm{O}$ concentrations for the nine crucible glasses measured (Fig. 8). This relationship holds despite the crucible glasses having a wide range 
of network modifying $\mathrm{CaO}$ (from 2.74 to 11.88 mol.\%) and $\mathrm{K}_{2} \mathrm{O}$ (from 0 to $3.66 \mathrm{~mol} \%$ ) concentrations (Table 1).

\subsection{Glass Structural Models}

Overall, XAS data and analyses for the glasses indicate nearest-neighbor iodide environments that contain the most common network-modifying cation species for that specific glass. Most glasses measured have $\mathrm{Na}$ as the most common network-modifier, and

correspondingly, XAS indicates I-sites with $\mathrm{Na}^{+}$nearest-neighbors, while the two glasses having $\mathrm{Li}$ as the most common network-modifying cation, have I-sites with shorter I-Li distances and smaller numbers of $\mathrm{Li}^{+}$nearest-neighbors, than I-Na sites in glass. All iodinesites in these glasses are within network-modifying domains and are portrayed in Figure 9 as an overall average site from the EXAFS findings, with two I-Na distances at $3.04 \AA$ and two I-Li distances at $2.80 \AA$ A an equivalent iodine environment with four $\mathrm{Na}^{+}$nearest-neighbors is similar to the $\mathrm{INa}_{4}$ tetrahedra in NaI-sodalite (see Fig. 12 in ref. [5]). Considering the overall glass compositions, iodine occurs rarely in the glass structure compared with the major chemical components, or only once in 20 times the volume depicted in Figure 9.

\subsection{Iodine versus Chlorine in Borosilicate Waste Glass}

Despite both iodine and chlorine anions being halogens with similar bonding characteristics in crystalline phases, $\mathrm{I}^{-}$and $\mathrm{Cl}^{-}$behave differently in borosilicate glass. Iodine-sites in the borosilicate glasses investigated here have relatively simple 
configurations compared with chorine-sites in similar waste glasses [33]. Iodine nearestneighbors are $\mathrm{Na}^{+}$or $\mathrm{Li}^{+}$, the most common network modifying cations in the glass. On the other hand, chlorine in glass shows an affinity for $\mathrm{Ca}^{2+}$, and can be bonded to itself, $\mathrm{Na}$, or oxygen [33]. According to the XAS results found here, iodine shows no inclination to bond with $\mathrm{Ca}^{2+}$, even though there are significant $\mathrm{Ca}$ concentrations in two of the glasses investigated, KI-2 and 10S-G-86F (Table 1).

This behavior difference may be due, in part, to differences in ionic radii. $\mathrm{Cl}^{-}$has a considerably smaller ionic radius $(1.81 \AA)$ than $\mathrm{I}^{-}(2.20 \AA)$ [34]. As a result, chloride has a larger charge density than iodide, which would result in chloride having a greater affinity for the higher charged cations in the glass, such as $\mathrm{Ca}^{2+}$.

\section{Conclusions}

Iodine K-edge XAS data and analyses for eleven borosilicate glasses, indicate iodide-like environments in the glass structure, where $\mathrm{I}^{-}$has $\mathrm{Na}^{+}$or $\mathrm{Li}^{+}$nearest-neighbors that are the most common network-modifying cation-type for that glass. Iodine with $\mathrm{Na}^{+}$ nearest-neighbors is in configurations similar to tetrahedral $\mathrm{INa}_{4}$ found in NaI-sodalite. Compared with alkali-halides, iodine environments with nearest neighbor $\mathrm{Na}^{+}$or $\mathrm{Li}^{+}$are considerably different in silicates, by having shorter I-cation distances as well as fewer coordinating cations. Overall, the iodine XAS findings indicate the important role of $\mathrm{Na}$ and $\mathrm{Li}$ in facilitating the retention of iodine in the glass structure. This is further supported by the observed dependence of iodine concentration on the combined $\mathrm{Na}_{2} \mathrm{O}+\mathrm{Li}_{2} \mathrm{O}$ content in 
the glass. Iodine also shows distinct differences from chlorine in terms of the preferred sites in the glass structure.

\section{Acknowledgments}

We thank Syed Khalid at NSLS Beam Line X18-B for his assistance with the experimental set-up and the XAS data collection. This work was supported in part by the U.S. Department of Energy (DOE) Office of River Protection through EnergySolutions, Inc. 


\section{References}

[1] "Final Tank Closure and Waste Management Environmental Impact Statement for the Hanford Site, Richland, Washington,” DOE/EIS-0391, U.S. Department of Energy, November 2012.

[2] S.N. Crichton, T.J. Barbieri, M. Tomozawa, in: V. Jain, R. Palmer (Eds.), Proc. Ceram. Trans: Env. Issues Waste Manag. Tech. Ceram. Nucl. Ind, vol. 61, The American Ceramics Society, Inc., Westville, OH, 1995, pp. 283-290.

[3] K.S. Matlack, H. Abramowitz, M. Brandys, I.S. Muller, D.A. Callow, N. D’Angelo, R. Cecil, I. Joseph, and I.L. Pegg, "Technetium Retention in WTP LAW Glass with Recycle Flow-Sheet: DM10 Melter Testing," VSL-12R2640-1, Rev. 0, Vitreous State Laboratory, The Catholic University of America, Washington, DC, 9/24/12.

[4] I. Bonhoure, A,M, Schiedegger, E. Wieland, and R. Dähn, Radiochim Acta, 90 (2002) 647.

[5] B.J. Riley, M.J. Schwieger, D.-S. Kim, W.W. Lukens, Jr., B.D. Williams, C. Iovin, C.P. Rodriguez, N.R. Overman,M.E. Bowden, D.R. Dixon, J.V. Crum, J.S. McCloy, and A. A. Kruger, Journal of Nuclear Materials, 452 (2014) 178.

[6] T. Kaneko, M. Ueda, S. Nagamatsu, T. Konishi, T. Fujikawa, and M. Mizumaki, Journal of Physics: Conference Series 190 (2009) 12062.

[7] Y. S. Shimamoto and Y. Takahashi, Analytical Sciences (Japan), 24 (2008) 405. 
[8] Y. S. Shimamoto, Y. Takahashi, Y. Terada, Environmental Science and Technology, 45 (2011) 2086.

[9] S. Kodama, Y. Takahashi, K. Okumura, and T. Uruga, Science of the Total Environment 363 (2006) 275.

[10] W.A. Reed, I. May, F. R. Livens, J. M. Charnock, A. P. Jeapes, M. Gresley, R. M. Mitchell, and P. Knight, J. Anal. At. Spectrom. 17 (2002) 541.

[11] X. Hou, V. Hansen, A. Aldahan, G. Possnert, O. C. Lind, G. Lujaniene, Anal. Chim. Acta. 632 (2009) 181.

[12] M. C. Feiters, F. C. Kupper, and W. Meyer-Klaucke, J. Synch. Rad. 12 (2005) 85.

[13] K. Yagi,a S. Umezawa, ${ }_{a} H$. Terauchi $i_{a}$ and H. Kasatanib J. Synchrotron Rad. 8 (2001) 803.

[14] B. Beagley, C.M.B. Henderson, and D. Taylor, Mineralogical Magazine 46 (1982) 459.

[15] J.A. Bearden and A.F. Burr, Rev. Mod. Phys. 39 (1967) 125.

[16] R.W.G. Wyckoff, Crystal Structures, v.2 p. 389 (John Wiley \& Sons, New York: 1964).

[17] K. Stadnicka, A.M. Glazer, J.R.L. Moxon, J. Appl Cryst., 18 (1985) 237.

[18] S. Ghose, Cheng Wan, O. Wittke, Acta Cryst., B 34 (1978) 84. 
[19] H. Kasatani, S. Aoyagi, Y. Kuroiwa, K. Yagi, R. Katayama, and H. Terauchi, Nucl. Instr. and Methods in Phys. Res., B199 (2003) 49.

[20] R.G.W. Wyckoff, Crystal Structures, v. 1, p. 88 (John Wiley \& Sons, New York: 1965).

[21] R.G.W. Wyckoff, Crystal Structures, v. 1, p. 87 (John Wiley \& Sons, New York: 1965).

[22] J. Verbist, P. Piret, and M. van Meerssche, Bulletin de la Societe Francaise de Mineralogie et de Cristallographie, 93 (1970) 509.

[23] G. Thiele and D. Putzas, Zeits. anorg. allg. Chem., 519 (1984) 217.

[24] K.S. Matlack, W. Gong, I.S. Muller, and I.L. Pegg, "DuraMelter 100 Tests to Support LAW Glass Formulation Correlation Development," Final Report, VSL06R6480-1, Rev. 0, Vitreous State Laboratory, The Catholic University of America, Washington, DC, 3/21/06.

[25] K.S. Matlack, I.S. Muller, W. Gong, and I.L. Pegg, "Small Scale Melter Testing of LAW Salt Phase Separation," Final Report, VSL-07R7480-1, Rev. 0, Vitreous State Laboratory, The Catholic University of America, Washington, DC, 08/20/07.

[26] M. Pasternak and R.D. Taylor, Phys. Rev., B37 (1988) 8130.

[27] W.T. Elam, B.Ravel, and J.R. Sieber, Radiat. Phys. Chem., 63 (2002) 121. 
[28] D.E. Sayers and B.A. Bunker in: X-ray Absorption Principles, Applications, Techniques of EXAFS, SEXAFS, and XANES, ed. D.C. Kroningsberger, R. Prins (Wiley, New York, 1988), p. 211.

[29] M. Newville, B. Ravel, D. Haskel, E.A. Stern, and Y. Yacoby, Phyica B 208-209 (1995) 154.

[30] S.I. Zabinsky, J.J. Rehr, A. Ankudinov, R.C. Albers, and M.J. Eller, Phys. Rev. Letters, B 52 (1995) 2995.

[31] M.O. Krause and J.H. Oliver, J. Phys. Chem. Ref. Data 8 (1979) 329.

[32] E.A. Stern in: X-ray Absorption Principles, Applications, Techniques of EXAFS, SEXAFS, and XANES, ed. D.C. Kroningsberger, R. Prins (Wiley, New York, 1988), p. 11.

[33] D.A. McKeown, H. Gan, I.L. Pegg, W.C. Stolte, and I.N. Demchenko, J. Nuclear Materials, 408 (2011) 236.

[34] R.D. Shannan, Acta Cryst., A32 (1976) 751. 
Table 1. Major oxide compositions from normalized XRF analyses (mol. \%) of the glasses: from high to low iodine content. Uncertainties are less than or equal to $10 \%$ of the value listed. $*=$ target composition.

\begin{tabular}{|c|c|c|c|c|c|c|}
\hline Glass & $\begin{array}{c}\text { Network } \\
\text { Modifiers }\end{array}$ & $\begin{array}{l}\text { Network } \\
\text { Formers }\end{array}$ & $\begin{array}{c}\text { Transition } \\
\text { Metals }\end{array}$ & $I^{b}$ & Others & Total \\
\hline NaI-3 & $\begin{array}{cc}\mathrm{Na}_{2} \mathrm{O} & 24.91 \\
\mathrm{CaO} & 3.47\end{array}$ & 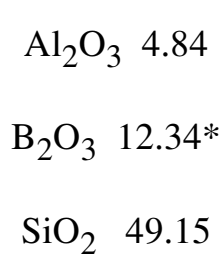 & $\begin{array}{l}\mathrm{ZnO} 2.35 \\
\mathrm{ZrO}_{2} 2.26 \\
\mathrm{Fe}_{2} \mathrm{O}_{3} 0.01\end{array}$ & 0.66 & & 100.0 \\
\hline NaI-6 & $\begin{array}{rr}\mathrm{Na}_{2} \mathrm{O} & 25.37 \\
\mathrm{CaO} & 3.40\end{array}$ & 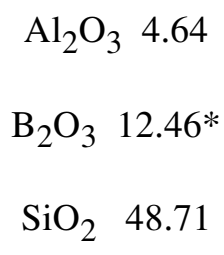 & $\begin{array}{l}\mathrm{SnO}_{2} 2.38 \\
\mathrm{ZnO} 2.41 \\
\mathrm{Fe}_{2} \mathrm{O}_{3} 0.01\end{array}$ & 0.63 & & 100.0 \\
\hline $\mathrm{NaI}-2$ & $\begin{array}{cc}\mathrm{Na}_{2} \mathrm{O} & 23.51 \\
\mathrm{CaO} & 3.04\end{array}$ & 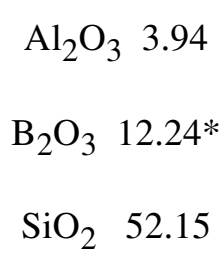 & $\begin{array}{l}\mathrm{ZnO} 2.46 \\
\mathrm{ZrO}_{2} 2.06 \\
\mathrm{Fe}_{2} \mathrm{O}_{3} 0.01\end{array}$ & 0.60 & & 100.0 \\
\hline NaI-5 & $\begin{array}{cc}\mathrm{Na}_{2} \mathrm{O} & 22.54 \\
\mathrm{CaO} & 3.66\end{array}$ & $\begin{array}{cc}\mathrm{Al}_{2} \mathrm{O}_{3} & 5.16 \\
\mathrm{~B}_{2} \mathrm{O}_{3} & 12.36^{*} \\
\mathrm{SiO}_{2} & 50.89\end{array}$ & 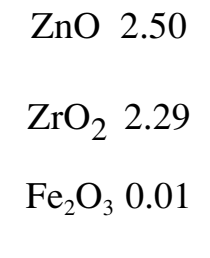 & 0.57 & & 100.0 \\
\hline KI-3 & $\begin{array}{cc}\mathrm{Na}_{2} \mathrm{O} & 21.53 \\
\mathrm{CaO} & 2.74 \\
\mathrm{~K}_{2} \mathrm{O} & 3.22\end{array}$ & $\begin{array}{l}\mathrm{Al}_{2} \mathrm{O}_{3} \\
\mathrm{~B}_{2} \mathrm{O}_{3}\end{array}$ & $\begin{array}{ll}\mathrm{ZnO} & 2.58 \\
\mathrm{ZrO}_{2} & 2.38 \\
\mathrm{Fe}_{2} \mathrm{O}_{3} & 0.01 \\
\mathrm{TiO}_{2} & 0.06\end{array}$ & 0.37 & & 100.0 \\
\hline KI-2 & $\begin{array}{l}\mathrm{Li}_{2} \mathrm{O} 9.42 * \\
\mathrm{Na}_{2} \mathrm{O} 8.65\end{array}$ & $\begin{array}{c}\mathrm{Al}_{2} \mathrm{O}_{3} 6.07 \\
\mathrm{~B}_{2} \mathrm{O}_{3} 8.99 *\end{array}$ & $\begin{array}{cc}\mathrm{ZnO} & 2.20 \\
\mathrm{ZrO}_{2} & 2.00 \\
\mathrm{Fe}_{2} \mathrm{O}_{3} & 0.01\end{array}$ & 0.14 & & 100.0 \\
\hline
\end{tabular}




\begin{tabular}{|c|c|c|c|c|c|c|}
\hline & $\begin{array}{ll}\mathrm{CaO} & 11.88 \\
\mathrm{~K}_{2} \mathrm{O} & 0.91\end{array}$ & $\mathrm{SiO}_{2} 49.73$ & $\mathrm{TiO}_{2} 0.01$ & & & \\
\hline NaI-1 & $\begin{array}{cc}\mathrm{Na}_{2} \mathrm{O} & 15.86 \\
\mathrm{CaO} & 3.37\end{array}$ & $\begin{array}{c}\mathrm{Al}_{2} \mathrm{O}_{3} 5.52 \\
\mathrm{~B}_{2} \mathrm{O}_{3} \\
12.30 * \\
\mathrm{SiO}_{2} \quad 58.10\end{array}$ & $\begin{array}{cc}\mathrm{ZnO} & 2.40 \\
\mathrm{ZrO}_{2} & 2.28 \\
\mathrm{Fe}_{2} \mathrm{O}_{3} & 0.01 \\
\mathrm{TiO}_{2} & 0.01\end{array}$ & 0.14 & & 100.0 \\
\hline KI-4 & $\begin{array}{cc}\mathrm{Na}_{2} \mathrm{O} & 19.01 \\
\mathrm{CaO} & 2.82 \\
\mathrm{~K}_{2} \mathrm{O} & 3.66\end{array}$ & $\begin{array}{l}\mathrm{Al}_{2} \mathrm{O}_{3} 4.35 \\
\mathrm{~B}_{2} \mathrm{O}_{3} 9.56^{*} \\
\mathrm{SiO}_{2} 55.53\end{array}$ & $\begin{array}{cc}\mathrm{ZnO} & 2.56 \\
\mathrm{ZrO}_{2} & 2.38 \\
\mathrm{Fe}_{2} \mathrm{O}_{3} & 0.01 \\
\mathrm{TiO}_{2} & 0.02\end{array}$ & 0.12 & & 100.0 \\
\hline KI-5 & $\begin{array}{cc}\mathrm{Na}_{2} \mathrm{O} & 19.34 \\
\mathrm{CaO} & 2.76 \\
\mathrm{~K}_{2} \mathrm{O} & 2.80\end{array}$ & $\begin{array}{c}\mathrm{Al}_{2} \mathrm{O}_{3} 4.33 \\
\mathrm{~B}_{2} \mathrm{O}_{3} \\
10.46^{*} \\
\mathrm{SiO}_{2} 55.51\end{array}$ & $\begin{array}{l}\mathrm{ZnO} 2.46 \\
\mathrm{ZrO}_{2} 2.24\end{array}$ & 0.11 & & 100.0 \\
\hline $10 \mathrm{~S}-\mathrm{G}-86 \mathrm{~F}$ & $\begin{array}{cc}\mathrm{Li}_{2} \mathrm{O} & 9.00^{*} \\
\mathrm{Na}_{2} \mathrm{O} & 5.42 \\
\mathrm{MgO} & 4.98 \\
\mathrm{CaO} & 8.25 \\
\mathrm{~K}_{2} \mathrm{O} & 0.43\end{array}$ & $\begin{array}{l}\mathrm{Al}_{2} \mathrm{O}_{3} 3.36 \\
\mathrm{~B}_{2} \mathrm{O}_{3} 9.03 * \\
\mathrm{SiO}_{2} 50.83\end{array}$ & $\begin{array}{cc}\mathrm{Cr}_{2} \mathrm{O}_{3} & 0.06 \\
\mathrm{Fe}_{2} \mathrm{O}_{3} & 2.29 \\
\mathrm{NiO} & 0.03 \\
\mathrm{TiO}_{2} & 1.24 \\
\mathrm{ZnO} & 2.81 \\
\mathrm{ZrO}_{2} & 1.49\end{array}$ & 0.04 & $\begin{array}{c}\mathrm{Cl} 0.21 \\
\mathrm{P}_{2} \mathrm{O}_{5} 0.10 \\
\mathrm{SO}_{3} 0.43\end{array}$ & 100.0 \\
\hline $10 \mathrm{~T}-\mathrm{G}-106 \mathrm{C}$ & $\begin{array}{cc}\mathrm{Na}_{2} \mathrm{O} & 19.32 \\
\mathrm{MgO} & 2.50 \\
\mathrm{CaO} & 2.51 \\
\mathrm{~K}_{2} \mathrm{O} & 4.03\end{array}$ & $\begin{array}{l}\mathrm{Al}_{2} \mathrm{O}_{3} 4.05 \\
\mathrm{~B}_{2} \mathrm{O}_{3} 9.84^{*} \\
\mathrm{SiO}_{2} 48.56\end{array}$ & $\begin{array}{cc}\mathrm{Cr}_{2} \mathrm{O}_{3} & 0.08 \\
\mathrm{Fe}_{2} \mathrm{O}_{3} & 2.46 \\
\mathrm{NiO} & 0.03 \\
\mathrm{TiO}_{2} & 1.41 \\
\mathrm{ZnO} & 2.92 \\
\mathrm{ZrO}_{2} & 1.59\end{array}$ & 0.03 & $\begin{array}{c}\mathrm{Cl} 0.23 \\
\mathrm{P}_{2} \mathrm{O}_{5} 0.11 \\
\mathrm{SO}_{3} 0.34\end{array}$ & 100.0 \\
\hline
\end{tabular}


${ }^{a}$ The source of sodium was $\mathrm{NaOH}$ in NaI-1, NaI-2, NaI-3, NaI-6, KI-2 and KI-3; $\mathrm{NaNO}_{3}$ was used in all other glasses.

${ }^{b} \mathrm{NaI}$ was the source of iodine in NaI-1, NaI-2, NaI-3, and NaI-6 glasses. KI was the iodine source in KI-1 through KI-4 glasses. $\mathrm{NH}_{4} \mathrm{IO}_{3}$ was the iodine source in KI-5 and NaI-5 glasses. 
Table 2. Iodine EXAFS fitting results for $\mathrm{I}_{2}$ and the iodide standards using $\mathrm{s}_{0}{ }^{2}=1.0 . \mathrm{E}_{0}$ values are from 33,169.0 eV. The r-factor is a goodness of fit parameter that is a sum-ofsquares measure of the fractional misfit scaled to the magnitude of the data $[29,30]$. Uncertainties (in parentheses) calculated by IFEFFIT.

\begin{tabular}{|c|c|c|c|c|c|}
\hline$\frac{\text { Sample }}{\mathrm{NaI} \cdot 2\left(\mathrm{H}_{2} \mathrm{O}\right)}$ & $\underline{\text { r-factor }}$ & $\underline{\mathbf{E}_{0}}$ & $\underline{\mathbf{r}}(\AA)$ & $\underline{\mathbf{n}}$ (atoms) & $\underline{\boldsymbol{\sigma}}^{2}\left(\AA^{2}\right)$ \\
\hline $\mathrm{I}-\mathrm{Na}$ & & & & & \\
\hline $\begin{array}{l}\text { EXAFS } \\
\text { Actual [22]: }\end{array}$ & 0.074 & -6.0 & $\begin{array}{l}3.10(0.02) \\
3.21\end{array}$ & $\begin{array}{l}1.8(0.2) \\
1.0\end{array}$ & $0.0191(0.0032)$ \\
\hline $\begin{array}{l}\text { EXAFS } \\
\text { Actual [22]: }\end{array}$ & & & $\begin{array}{l}3.42(0.02) \\
3.26\end{array}$ & $\begin{array}{l}2.4(0.3) \\
1.0\end{array}$ & $0.0157(0.0026)$ \\
\hline $\mathbf{K I}$ & & & & & \\
\hline $\mathrm{I}-\mathrm{K}$ & & & & & \\
\hline $\begin{array}{l}\text { EXAFS } \\
\text { Actual [21]: }\end{array}$ & 0.033 & 3.5 & $\begin{array}{l}3.48(0.01) \\
3.53\end{array}$ & $\begin{array}{l}4.3(0.2) \\
6.0\end{array}$ & $0.0223(0.0027)$ \\
\hline I-I & & & & & \\
\hline $\begin{array}{l}\text { EXAFS } \\
\text { Actual [21]: }\end{array}$ & & & $\begin{array}{l}5.00(0.05) \\
4.99\end{array}$ & $\begin{array}{l}10.6(8.9) \\
12.0\end{array}$ & $0.0506(0.0229)$ \\
\hline
\end{tabular}

\section{$\mathrm{CaI}_{2} \cdot 4\left(\mathrm{H}_{2} \mathrm{O}\right)$}

$\mathrm{I}-\mathrm{Ca}$

$\begin{array}{llllll}\text { EXAFS } & 0.009 & 0.2 & 3.13(0.03) & 0.9(0.7) & 0.0293(0.0181) \\ \text { Actual [23]: } & & & 3.13 & 1.0 & \end{array}$

$\mathbf{I}_{2}$

I-I

$\begin{array}{llllll}\text { EXAFS } & 0.059 & 3.5 & 2.76(0.02) & 0.8(0.2) & 0.0167(0.0058) \\ \text { Actual [15]: } & & & 2.68 & 1.0 & \end{array}$

Table 3. Iodine EXAFS fitting results for the I-O distances in the iodate crystalline standards using $\mathrm{s}_{0}^{2}=1.0$. Conventions in Table 1 are used. 
$\underline{\text { Sample }} \quad \underline{\mathbf{r}}$-factor $\quad \underline{\mathbf{E}_{0}} \quad \underline{\mathbf{r}}(\AA) \quad \underline{\mathbf{n}}$ (atoms) $\quad \underline{\boldsymbol{\sigma}}^{2}\left(\AA^{2}\right)$

$\mathrm{NaIO}_{3}$

$\begin{array}{llllll}\text { EXAFS } & 0.025 & 14.0 & 1.81(0.01) & 3.2(0.4) & 0.0017(0.0013) \\ \text { Actual [16]: } & & & 1.82 & 3.0 & \end{array}$

$\mathrm{Ca}\left(\mathrm{IO}_{3}\right)_{2}$

$\begin{array}{llllll}\text { EXAFS } & 0.033 & 14.0 & 1.82(0.01) & 2.9(0.4) & 0.0013(0.0014) \\ \text { Actual [18]: } & & & 1.81 & 3.0 & \end{array}$

$\mathrm{KIO}_{3}$

$\begin{array}{ccclll}\text { EXAFS } & 0.024 & 14.0 & 1.82(0.01) & 3.1(0.1) & 0.0014(0.0013) \\ \text { EXAFS [13] } & & & 1.82 & 3.0 & 0.0010\end{array}$


Table 4. Iodine EXAFS fitting results for the glasses from high to low I-content. Na nearest neighbors (I-Na correlations) were used in the fits, unless otherwise noted. $\mathrm{s}_{0}{ }^{2}=$ 1.0. Conventions in Table 1 are used. ' $c$ ' indicates constrained parameter.

\begin{tabular}{|c|c|c|c|c|c|c|}
\hline Glass & $\begin{array}{l}{[\mathrm{I}]} \\
\text { mol.\% }\end{array}$ & $\underline{\mathbf{r}}$-factor & $\underline{\mathbf{E}}_{\mathbf{0}}(\mathrm{eV})$ & $\mathbf{r}(\AA)$ & $\underline{\text { n (atoms) }}$ & $\underline{\sigma}^{2}\left(\AA^{2}\right)$ \\
\hline NaI-3 & 0.66 & 0.016 & 1.0 & $3.04(0.01)$ & $4.0(0.7)$ & $0.0275(0.0044)$ \\
\hline NaI-6 & 0.63 & 0.054 & $1.0 \mathrm{c}$ & $3.04(0.02)$ & $4.7(1.6)$ & $0.0349(0.0098)$ \\
\hline NaI-2 & 0.60 & 0.033 & $1.0 \mathrm{c}$ & $3.04(0.02)$ & $5.1(1.7)$ & $0.0403(0.0102)$ \\
\hline NaI-5 & 0.57 & 0.040 & $1.0 \mathrm{c}$ & $3.05(0.02)$ & $3.5(1.1)$ & $0.0263(0.0083)$ \\
\hline KI-3 & 0.37 & 0.033 & $1.0 \mathrm{c}$ & $3.08(0.02)$ & $6.2(2.1)$ & $0.0412(0.106)$ \\
\hline $\begin{array}{l}\text { KI-2 } \\
\quad \begin{array}{l}\text { I-Li } \\
\text { I-Na }\end{array}\end{array}$ & 0.14 & $\begin{array}{l}0.005 \\
0.012\end{array}$ & $\begin{array}{l}5.6 \\
1.0 \mathrm{c}\end{array}$ & $\begin{array}{l}2.79(0.08) \\
3.04(0.04)\end{array}$ & $\begin{array}{l}3.5(1.8) \\
5.8(3.0)\end{array}$ & $\begin{array}{l}0.0134(0.0200) \\
0.0509(0.0197)\end{array}$ \\
\hline NaI-1 & 0.13 & 0.175 & $1.0 \mathrm{c}$ & $3.03(0.05)$ & $5.8(4.2)$ & $0.0452(0.0244)$ \\
\hline KI-4 & 0.12 & 0.083 & $1.0 \mathrm{c}$ & $3.04(0.04)$ & $3.2(2.6)$ & $0.0230(0.0223)$ \\
\hline KI-5 & 0.11 & 0.113 & $1.0 \mathrm{c}$ & $3.02(0.05)$ & $4.9(3.9)$ & $0.0386(0.0258)$ \\
\hline $\begin{array}{c}\text { 10S-G-86F } \\
\text { I-Li }\end{array}$ & 0.04 & 0.022 & 5.6 & $2.81(0.02)$ & $2.5(0.3)$ & $0.0030(0.0041)$ \\
\hline 10T-G-106C & 0.02 & 0.040 & $1.0 \mathrm{c}$ & $3.05(0.03)$ & $4.4(2.0)$ & $0.0329(0.0143)$ \\
\hline
\end{tabular}




\section{Figure Captions}

Fig. 1. Edge-step normalized iodine K-edge XANES spectra of the crystalline standards. Plots are offset for clarity. The more reduced species are the four lower spectra, and the oxidized species are the three upper spectra.

Fig. 2. Iodine XANES spectra of $\mathrm{I}_{2}$ and the iodide standards (color points and lines), plotted with the Na-dominated network modifier glasses measured (black lines).

Fig. 3. Iodine XANES spectra of the Na-dominated network modifier glasses (black lines) and Li-dominated network modifier glasses (red lines). Inset shows detailed differences between the two sets of glasses.

Fig. $4 \mathrm{a} . \mathrm{k}^{2} \chi(\mathrm{k})$ data (black points and line) and the fits (red line) for $\mathrm{I}_{2}$ and the iodide standards. Fitting results are presented in Table 2. Plots are offset for clarity.

Fig. $4 \mathrm{~b} . \mathrm{k}^{2} \chi(\mathrm{k})$ data comparison of the standards: iodates versus KI.

Fig. 4 c. $\mathrm{k}^{2} \chi(\mathrm{k})$ data comparison of the KI standard (green points and line) versus the Na-rich glasses (black lines). 
Fig. 4 d. $\mathrm{k}^{2} \chi(\mathrm{k})$ data comparison of the Na-dominated network modifier glasses (top plot) versus the Li-dominated network modifier glasses (bottom plot).

Fig. 5a. Partial RDF data (black points and line) and fits (red line) for $\mathrm{I}_{2}$ and the iodide standards. Plots are offset for clarity. IFEFFIT final fitting parameters reported in Table 2.

Fig. 5b. Partial RDF (top) and $\mathrm{k}^{2} \chi(\mathrm{k})$ (bottom) data (black points and lines) and fits (red line) for the iodate standard, $\mathrm{NaIO}_{3}$. IFEFFIT final fitting parameters reported in Table 3.

Fig. 6a. Partial RDF (top) and $\mathrm{k}^{2} \chi(\mathrm{k})$ (bottom) data (black points and line) and fits (red line) for the highest iodine-content glass, NaI-3. IFEFFIT final fitting parameters reported in Table 4.

Fig. 6b. Iodine partial RDF (top) and $\mathrm{k}^{2} \chi(\mathrm{k})$ (bottom) data (black points and line) and fits (red line: I-Li fit; blue line: I-Na fit) for the Li-dominated network modifier glass, KI-2. The different fit results and r-factors (Table 4) show that the I-Li model does slightly better than the I-Na model describing the KI-2 glass EXAFS data.

Fig. 7. Iodine environment nearest-neighbor distance $(r)$ versus coordination number $(n)$ for the crystalline standards and for the two glass types: Na-dominated network modifier glasses 
(blue) and Li-dominated network modifier glasses (purple). Actual values from crystal structure refinements for the standards are plotted as squares, and EXAFS fitting results are plotted as filled circles. EXAFS fitting results for the glasses are plotted as open circles.

Fig. 8. Measured iodine content as a function of $\mathrm{Na}_{2} \mathrm{O}+\mathrm{Li}_{2} \mathrm{O}$ content in the crucible glasses, in which iodine is over-batched (see Table 1 for compositions). Dominant network modifier cation chemistries are indicated.

Fig. 9. Hypothetical KI-2 glass structure depicting a possible I-site (purple) determined from XAS analysis results. Numbers of atoms for each major element type shown approximate the glass composition. However, the single I atom depicted is approximately 20 times the true atomic proportion for I in this glass. I-Na and I-Li distances and coordination numbers depict an overall average from the EXAFS fitting analyses results. If all cations coordinating to iodine are $\mathrm{Na}^{+}$, then the iodine-site would be similar to tetrahedral $\mathrm{INa}_{4}$ found in NaIsodalite. 


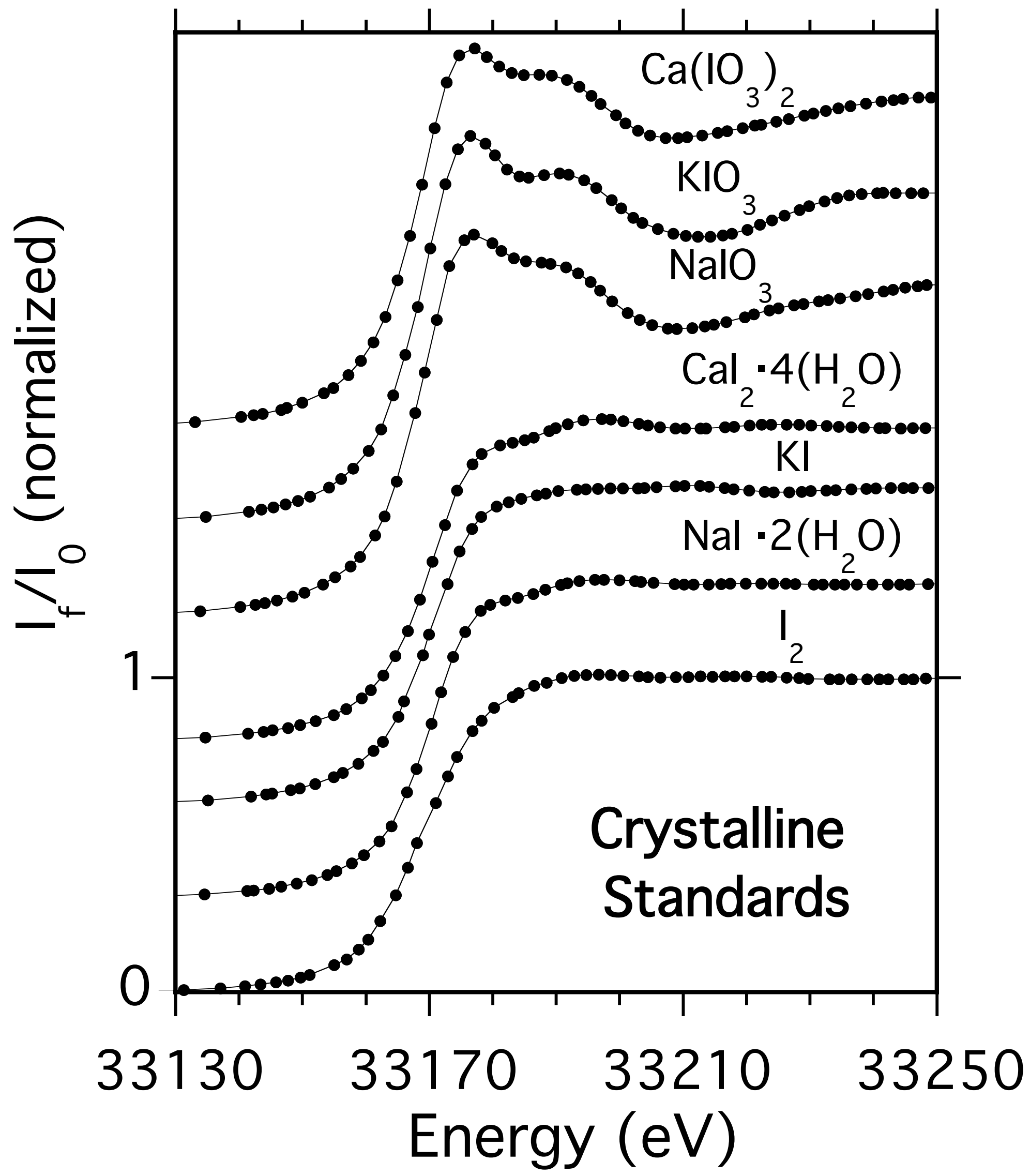

Fig. 1 
Figure 2

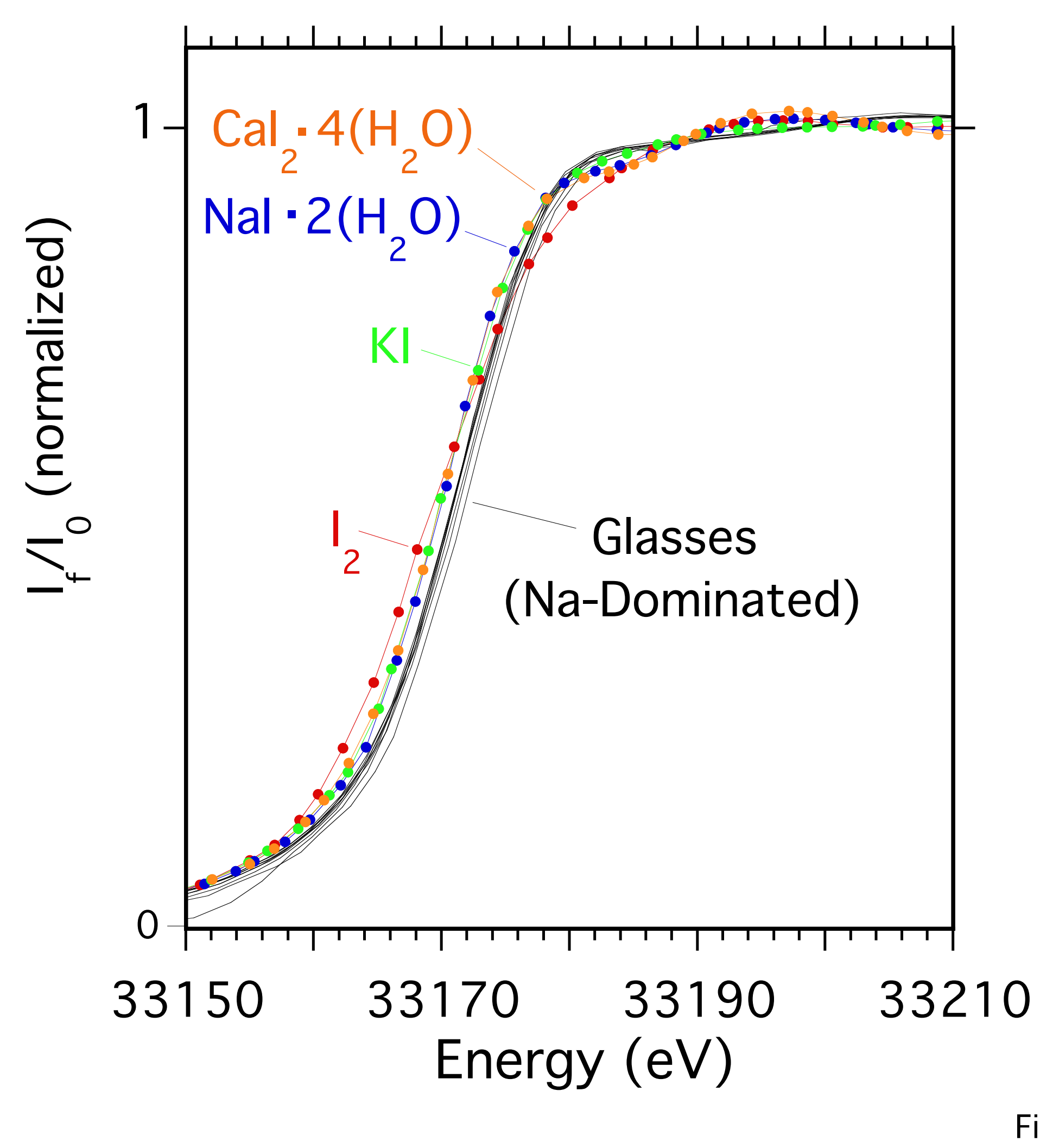

Fig. 2 


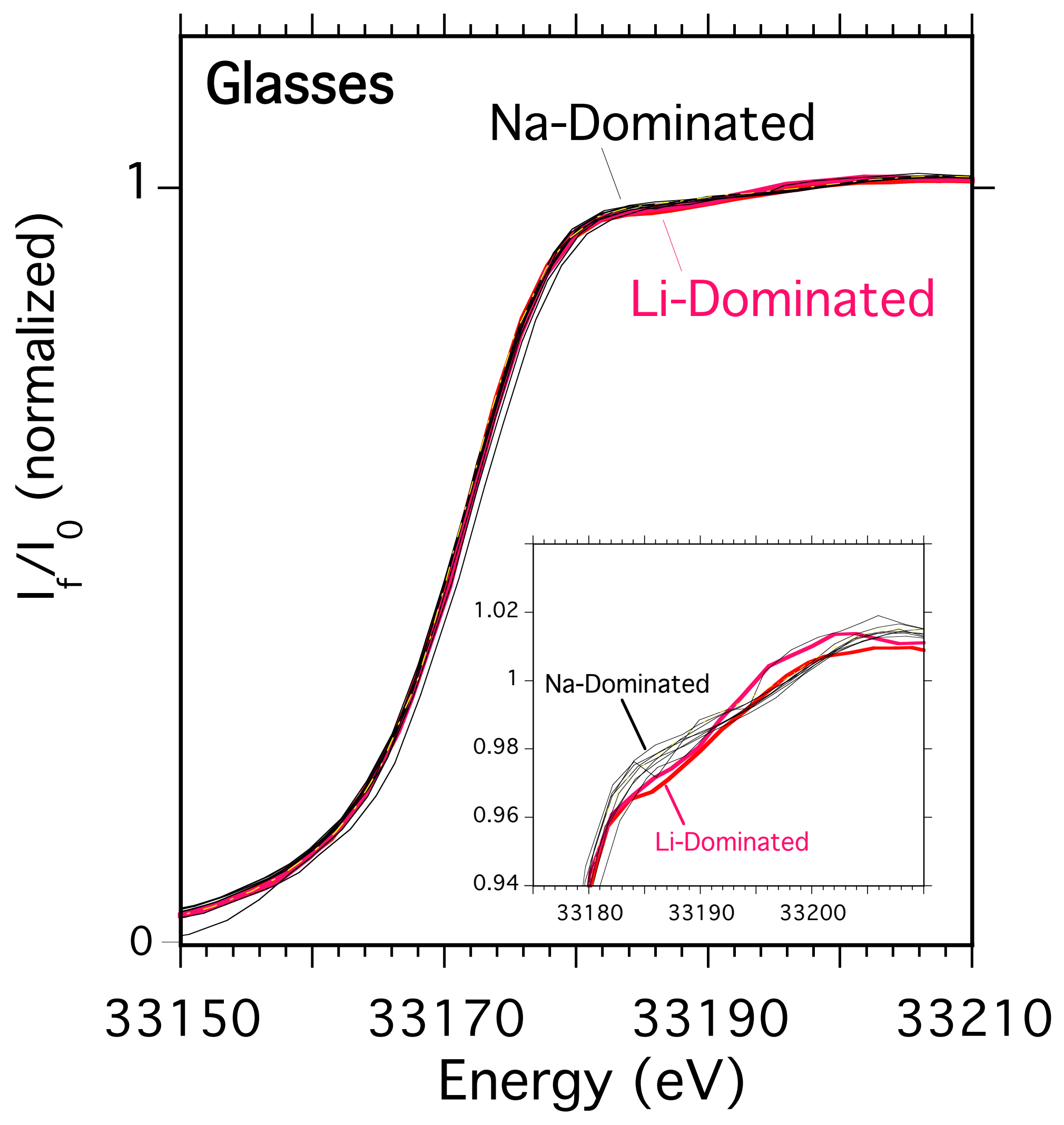

Fig. 3 


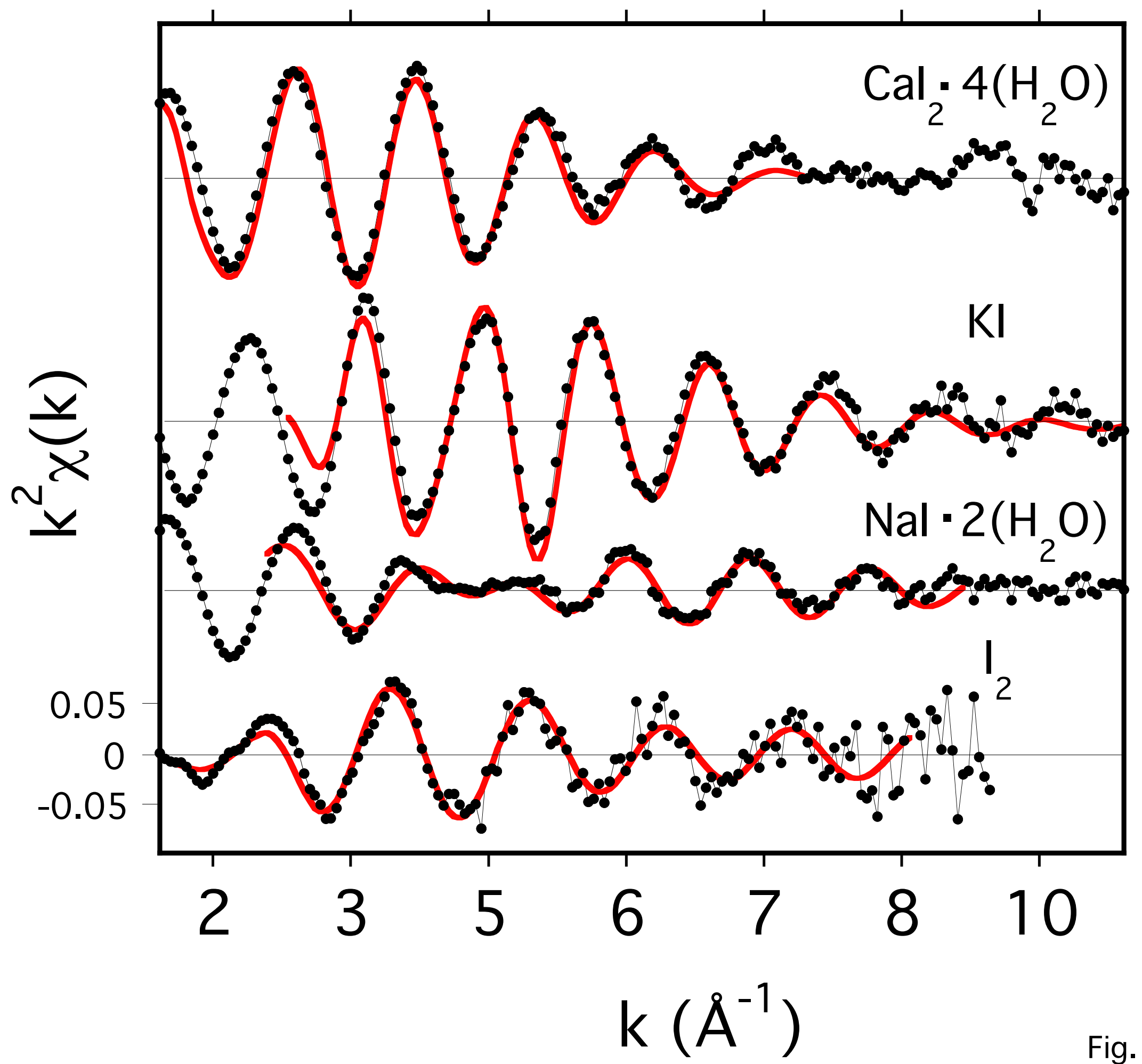

Fig. $4 a$ 


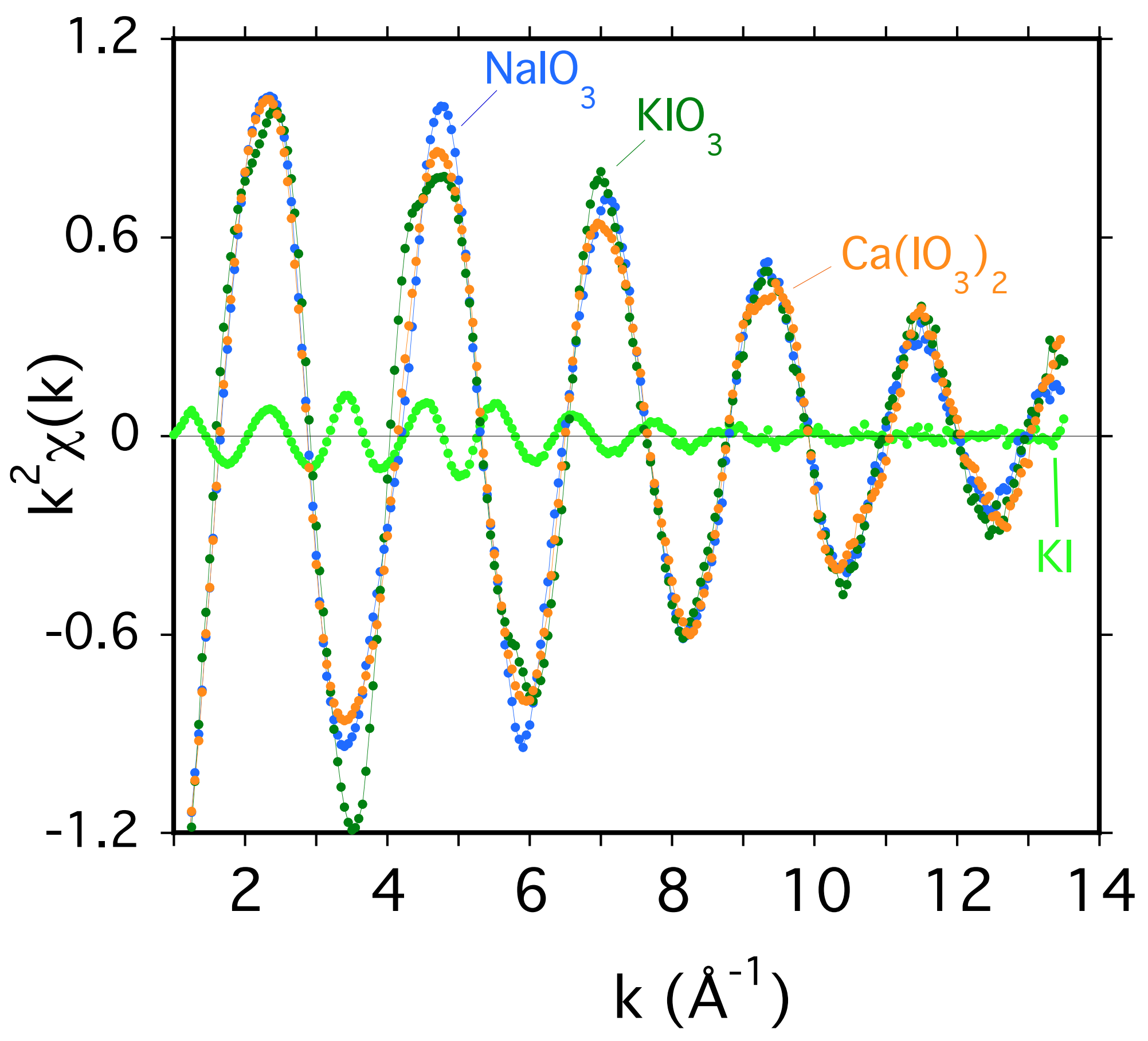

Fig. $4 b$ 


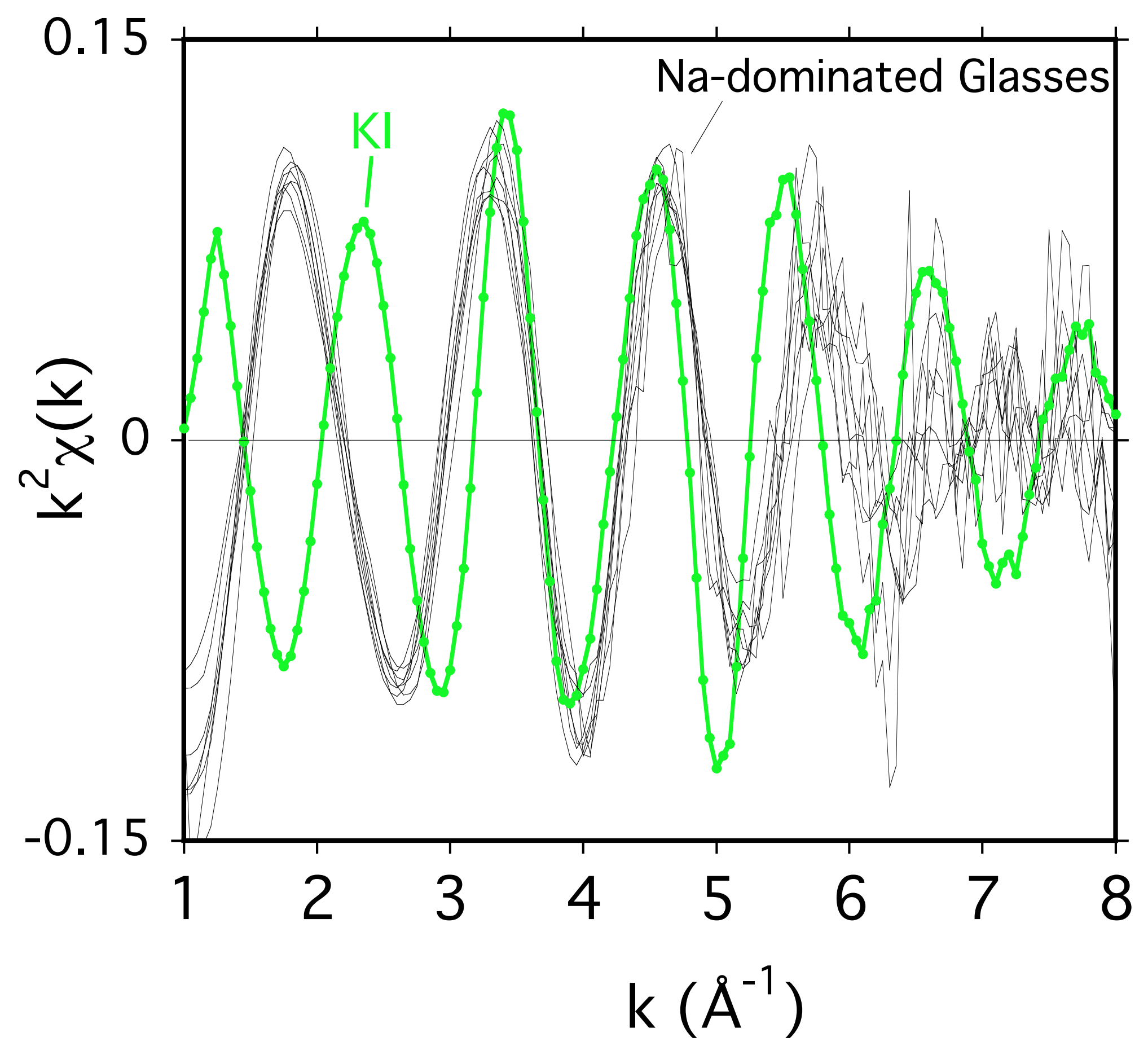

Fig. 4c 
Figure 4d

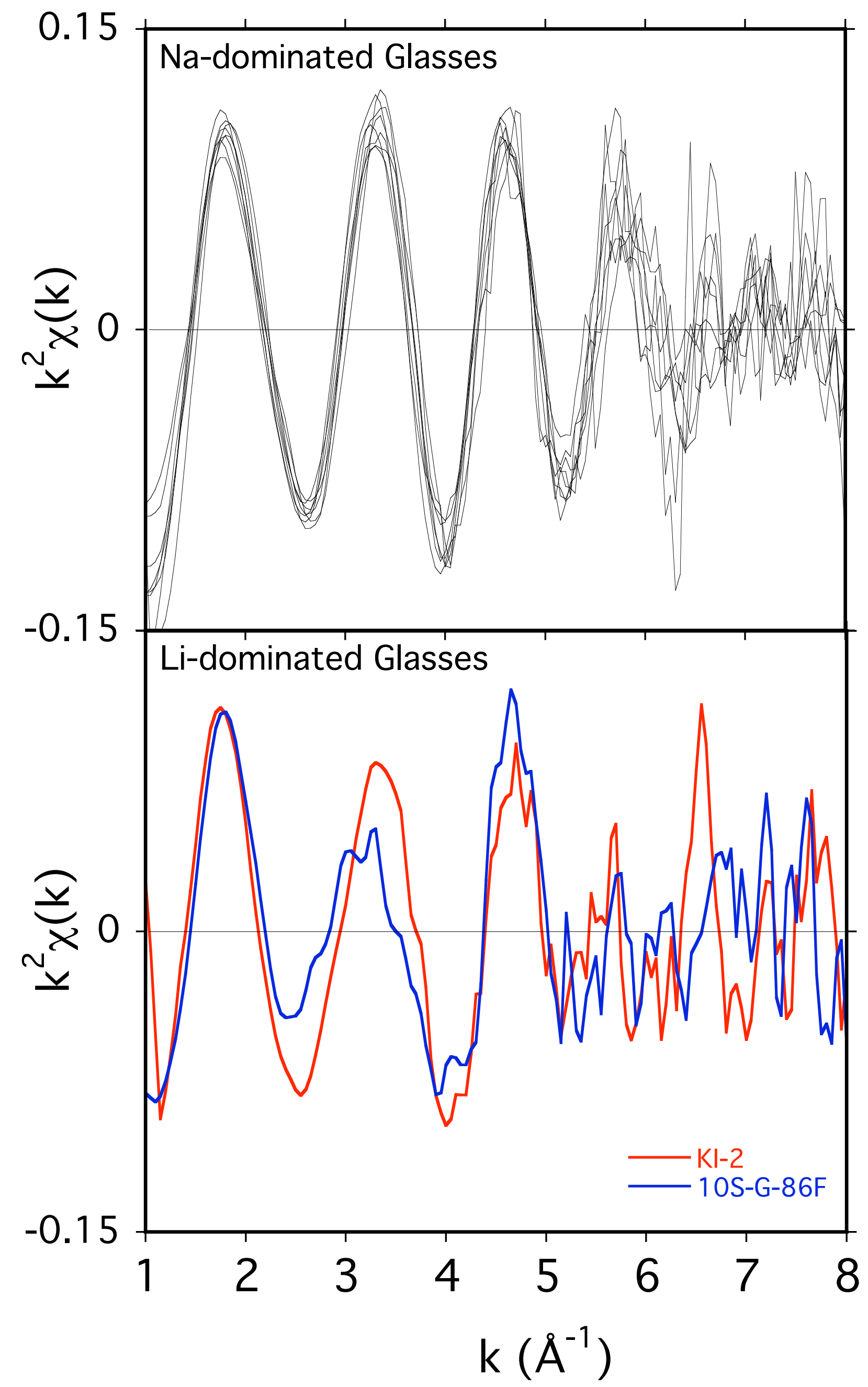

Fig. $4 d$ 


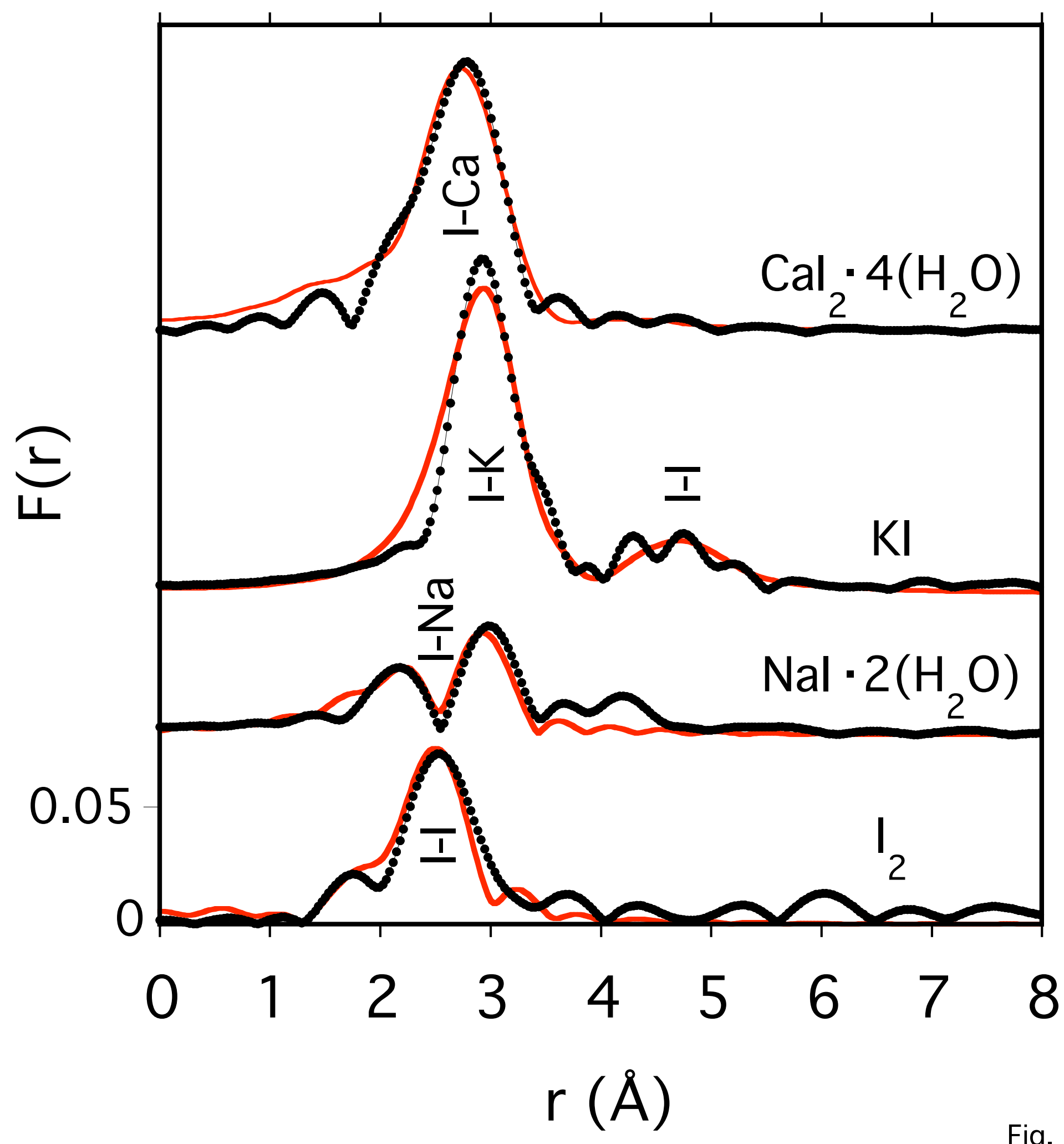

Fig. 5a 
Figure 5b
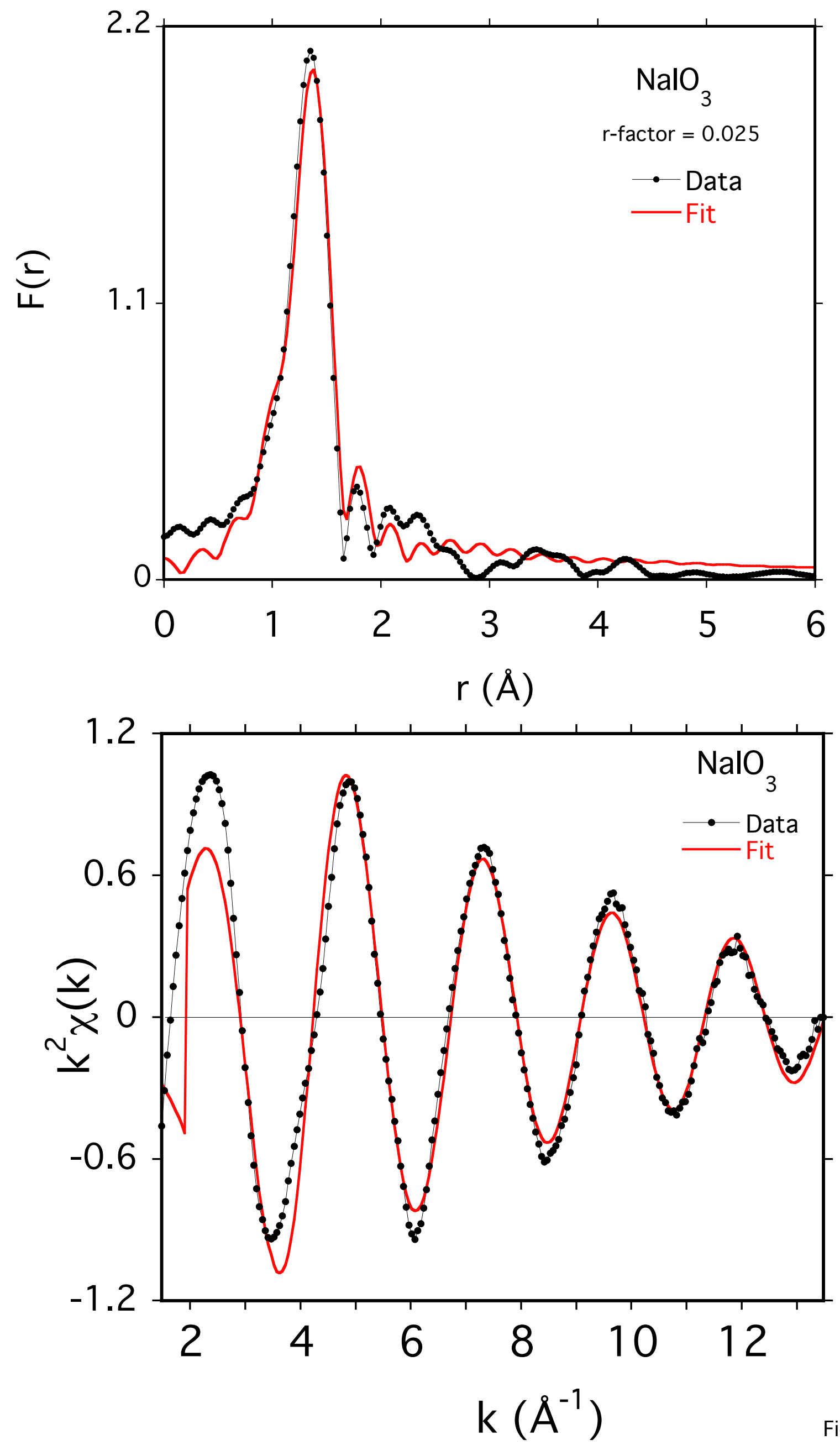

Fig. $5 b$ 

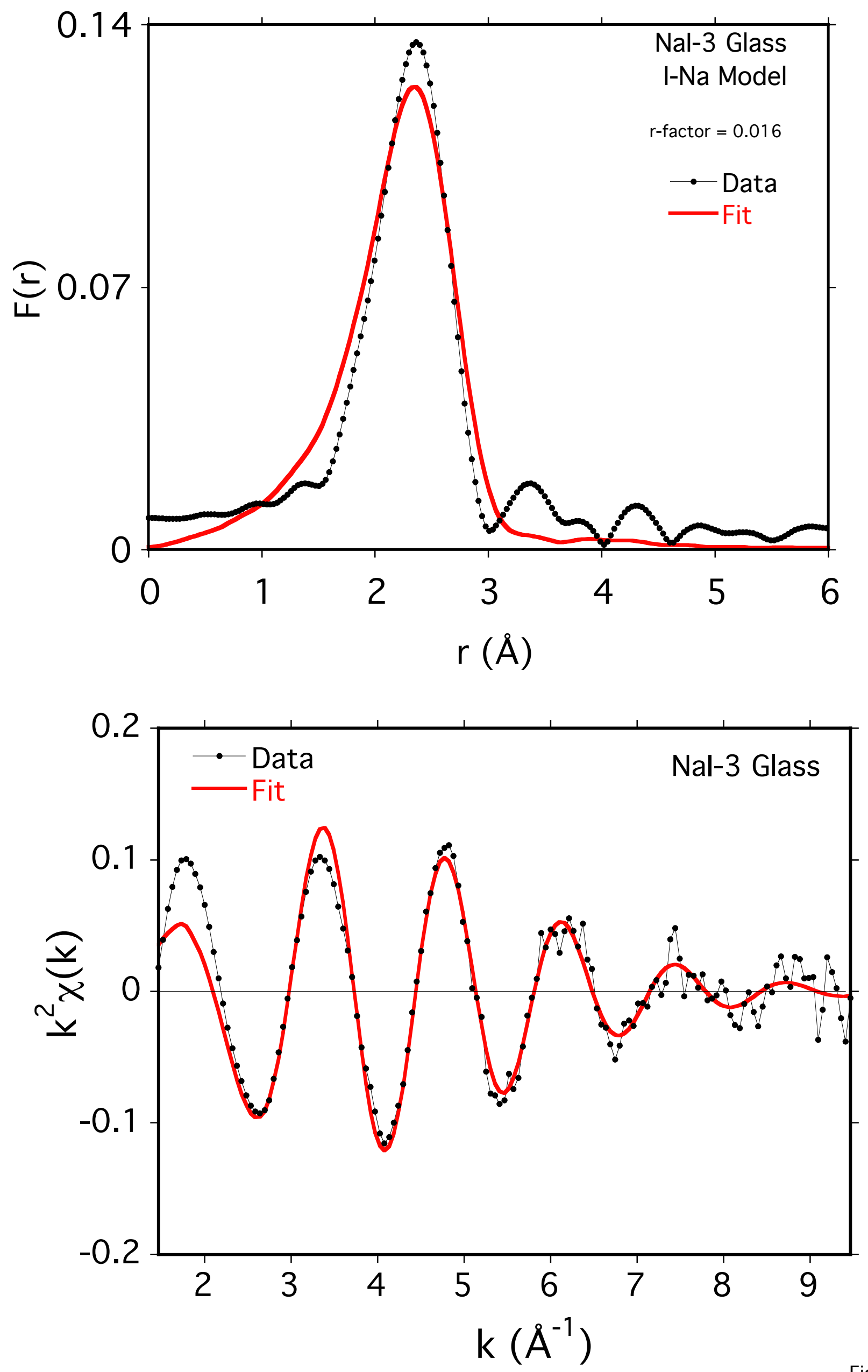

Fig. $6 a$ 

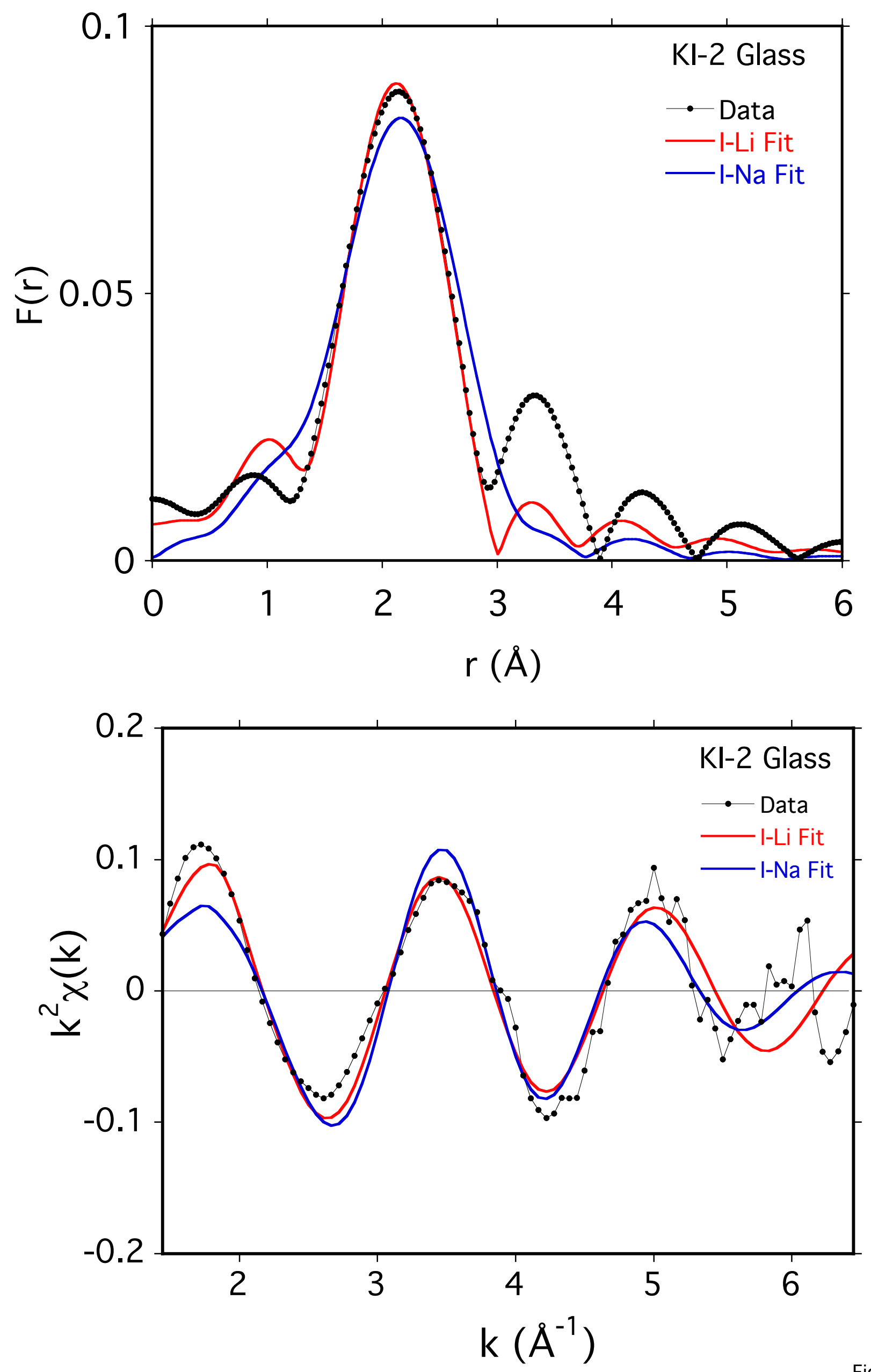

Fig. $6 b$ 


\section{lodine Environments}

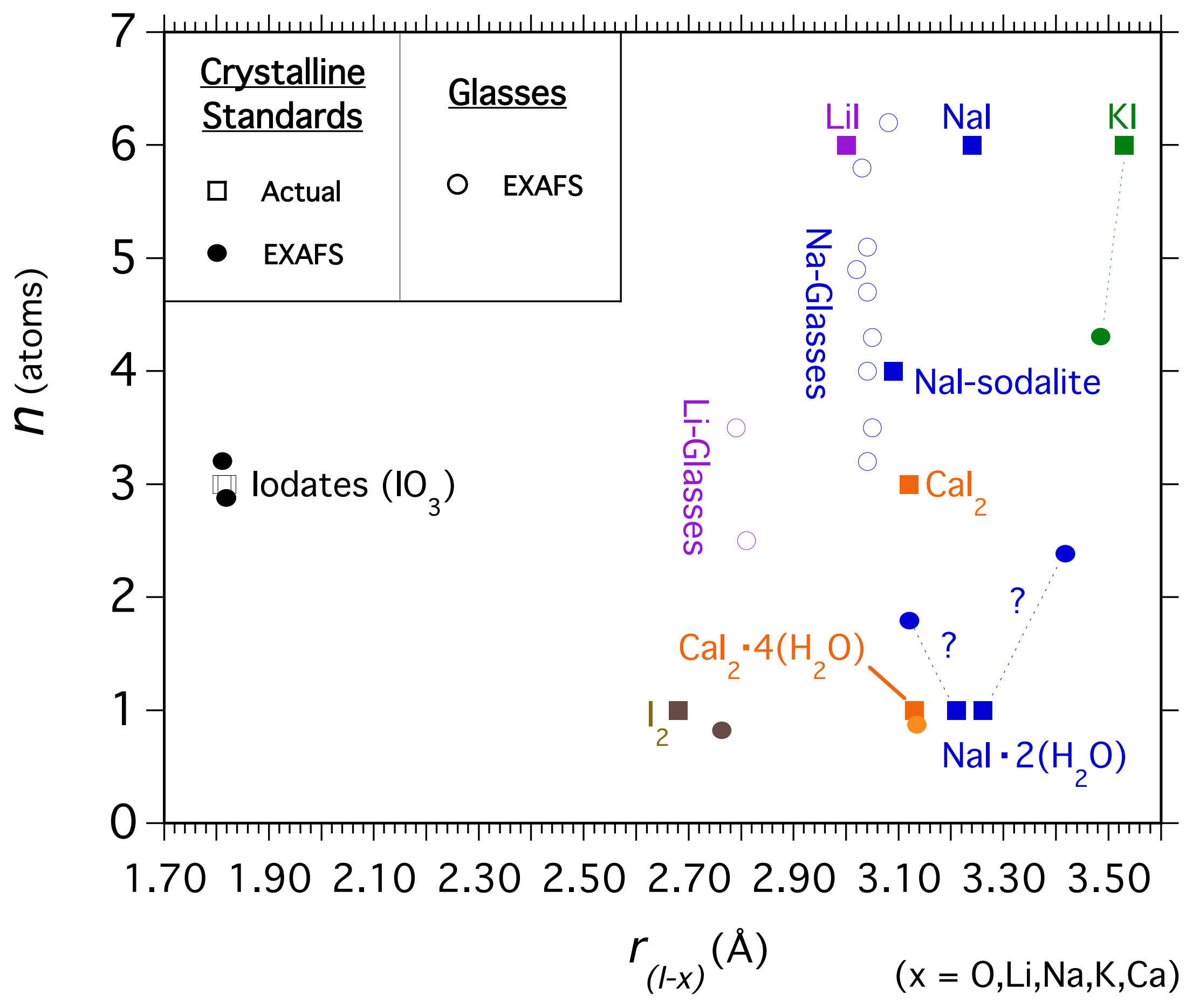

Fig. 7 
Figure 8

\section{lodine in Glass}

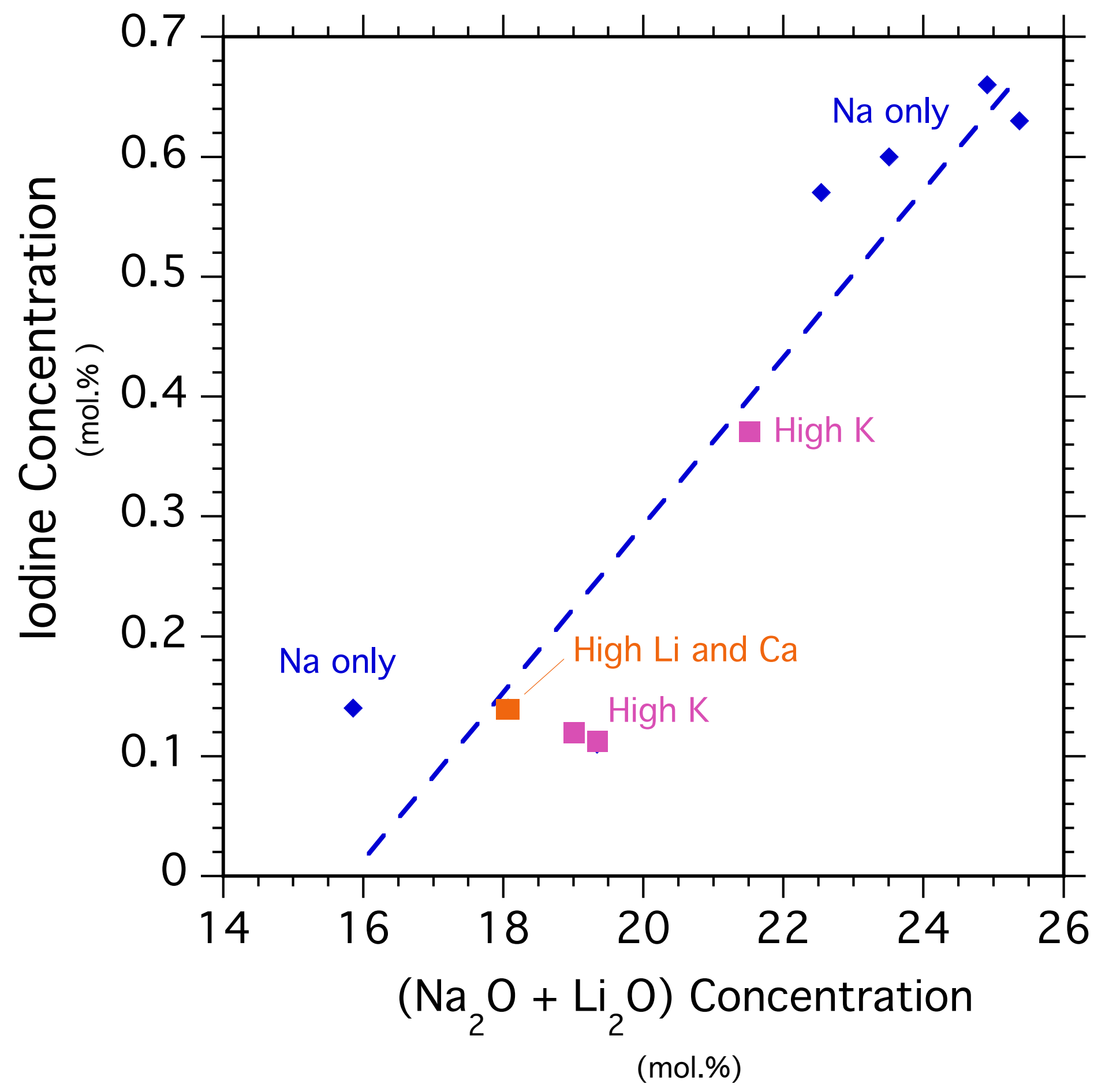

Fig. 8 


\section{Hypothetical Glass Structure}

Fig. 9
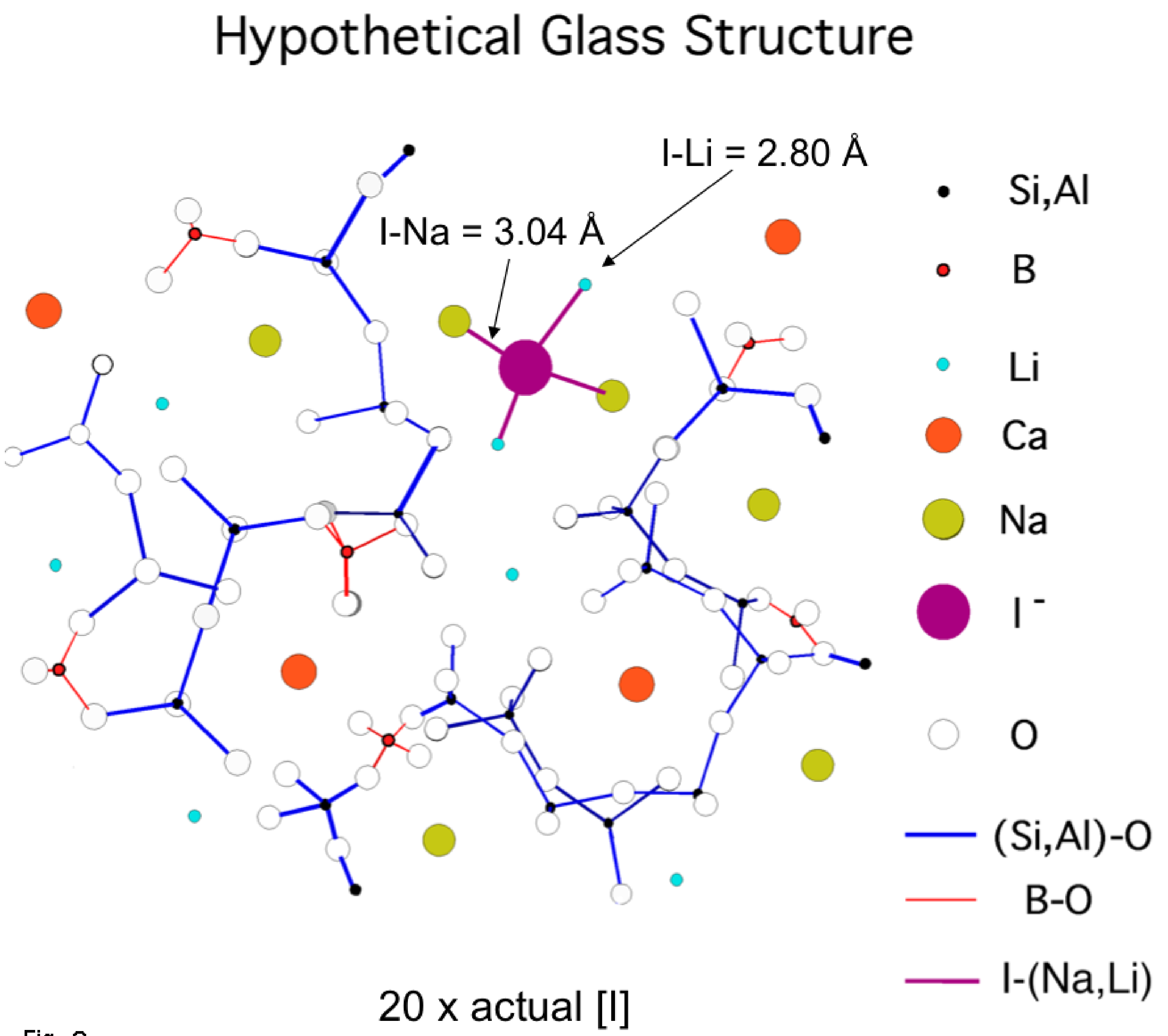

$\mathrm{Kl}-2$

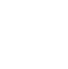

